Developing Mental Health Initiatives for Independent Schools in Canada

\title{
IDENTIFYING MENTAL HEALTH INITIATIVES FOR INDEPENDENTLY FUNDED CHRISTIAN ELEMENTARY SCHOOLS IN ONTARIO
}

\author{
by \\ Margaret Kloet \\ BA CYC, Ryerson University, 2009-2013 \\ An MRP presented to Ryerson University \\ In partial fulfillment of the requirements for the degree of \\ Master of Health Science \\ In the program of \\ Child and Youth Care
}

Toronto, Ontario, Canada, 2020

(C) Margaret Kloet, 2020

\section{Identifying Mental Health}

Initiatives in

Independently Funded Christian Elementary Schools,

Master of Health Sciences, 2020, Margaret Kloet, Child and Youth Care, 


\title{
Ryerson University
}

\begin{abstract}
This study seeks to understand the use of mental health strategies within independently funded Christian elementary Schools (IFCES), while considering how research literature identifies the implementation of mental health strategies in publicly funded elementary schools. There is a major research gap for IFCES in this area. This study used a qualitative approach via structured interviews to gather data reflecting how IFCES provide mental health supports. A wide variety of programming and supports within the schools (both IFECS and publicly funded) were identified during the research process. While the tiered system of support has been strongly considered in research literature (Sanchez, Cornacchio, Poznanski, Golik, Chou, \& Comer, 2018), the IFECS sector did not intentionally use this framework as a support to implement a mental health plan. This study identified that IFECS are gaining momentum in mental health programming and would benefit further from utilizing a framework to address their growing mental health needs.
\end{abstract}

Key Words: mental health in elementary schools, independently funded Christian schools, mental health program, Tier I-III, prevention, intervention 


\section{Introduction}

Children who experience mental health challenges benefit significantly from receiving access to supports during their early years (Williams, Horvath, Wei, VanDorn, Jonson-Reid, 2007). School settings continue to be identified as the most impactful resource for meeting the mental health needs of children (Cook, Frye, Slemrod, Lyon, Renshaw, Zhang, 2015). While considering prevention and intervention, Cook et. al., identify that approximately 1 in 5 children have identifiable mental health disorders (2015). Of those identified, approximately $50 \%$ do not receive the necessary support (Moon, Williford, Mendenhall, 2017). In an effort to combat this reality, much research has been done to better understand how to support students with mental health challenges within the school setting. Research has demonstrated the benefit of early intervention and evidence-based practices and interventions as key strategies to supporting elementary students with their mental health challenges (Mental Health Commission of Canada, 2013).

Children experience a range of supports geared toward mental health and wellness within the school; however, there is a distinct variation from school to school (Kilgus, Reinke, Jimerson, 2015). This study seeks to understand how these variations fit into the ecosystems of influence and how these variations compare between research literature and data gathered from independently funded elementary Christian school settings. Taking a closer look at these variations by way of Bronfenbrenner's Ecological theory will be a valuable tool to understand the variables impacting the mental health initiatives utilized in school settings (Bassett-Gunter, Yessis, Manske, \& Stockton. 2012).

As schools are identified as the medium for prevention and intervention of mental health strategies, establishing an agreed-upon approach remains undefined (Cook et al., 2015). This is largely due to the academic sector and medical sector and their varying theoretical perspectives on supporting the child (Basset-Gunter et al., 2012). Mental health intervention has predominantly come from a medical theory (evidence-based), and schools utilize an educational theory (constructivist perspectives) (Bassett-Gunter, Manske, Stockton, 2012). Bassett-Gunter et al. suggest the starting point of acknowledging the realization that mental health directly impacts academic outcomes (2012). The range of research literature continues to suggest that 
many interventions work independently of a potential framework and of each other, and thus do not address both needs (academic and mental) effectively or in collaboration with each other.

In response to this challenge, research literature has identified the value of integrating mental health frameworks, specifically Positive Behavioural Interventions and Supports (PBIS) with Social Emotional Learning (SEL) strategies (Cook et al., 2015) (Reinke, Herman, Ialongo, 2012). These studies have shown positive outcomes and recommend further combination of approaches to allow children to receive effective mental health prevention and intervention. Further contributions were made on behalf of the provincial government in funding the School Mental Health Ontario Action Plan 2019. This plan considers frameworks as mentioned and established via a tiered system that blends the mental health needs of a student within a framework that is familiar to the academic sector (School Mental Health Ontario, 2019). This framework proves to be an effective combination, addressing the needs and challenges that have been highlighted throughout research literature over the past 10 years. The Action Plan of 2019 may provide administrative staff and schools a solid point of reference and guidance when establishing their mental health plan for prevention and intervention.

There is an extensive amount of research literature surrounding the development of school mental health frameworks and interventions. What remains scarce is literature that pertains specifically to independently funded Christian elementary schools, along with research literature pertaining to the implementation of mental health prevention and intervention initiatives for their students. The significance here lies in the organizational structure and independence of elementary Christian schools. Privately run schools do not receive government funding and are required to follow various requirements as imposed by the Education Act (Ministry of Education Ontario, 2019). While there are ministry requirements to follow, the independence of the organization allows the school to promote the Christian faith and organize their school in a manner that suits their needs. Keeping this in mind highlights the potential for variation in educational services provided by the school and received by the consumer (the student). This study seeks to understand how this sector presently supports their students' mental health and wellness, and what strategies they implement to allow for prevention and intervention. The focus here strives to connect the literature to these findings to better 
understand the impact of effective mental health supports for children in Christian elementary schools.

\section{Social Location}

As the researcher of this study, it is important to understand my position within society and the lens in which I am doing the research from. I am a white middle-aged woman of Dutch heritage. I have a strong religious conviction to Christianity, and I am not considered to be in the low socioeconomic status. I have not experienced poverty. I come from an intact family and am married with children. Acknowledging my status is important in understanding the position from which I complete this research. I am interested in the prevention of mental health disparities among children and youth. I have worked extensively in an inpatient unit for children and youth who suffer from mental health challenges. Observing these struggles within this vulnerable population has motivated me to pursue early intervention and prevention to possibly allow for a different trajectory for the students who receive early intervention. My Christian faith has furthered this drive and convicted me to consider how this passion could be brought into the elementary Christian school community in which I now work. My focus springs up from the combination of my childhood experiences, my Christian faith and the community I live and participate in. I have gained the confidence of the Administration within the Christian school in which I work as a school counselor. I feel I am in a position of influence within the school I am employed along with the Christian school community that I am a part of, due to my visible dedication and engagement. It is this connection and influence that propels me to pursue this study.

I also am drawn to the use of tiered support systems and have a positive bias to the value of using this structure of support as an effective element in intervention. I also feel that it is within the school system that children will have the greatest chance of receiving effective mental health intervention and prevention opportunities. This is my position from which I am initiating change in the lives of our children, our youth and for our adults of tomorrow.

\section{Statement of Problem}

In considering independently funded Christian elementary schools, there is little to no research literature of mental health strategies and initiatives being implemented and/or studied. 
Also limited is a specific framework in which mental health programs are to be implemented. The research data as gathered through this qualitative study and gathered through research literature will assist in establishing a base of information for this sector.

\section{Purpose}

The intent of this study is to identify present day mental health supports and initiatives that are used within the independently funded Christian elementary school setting and how this compares to supports found within literature as being preventative and effective interventions for children. Literature provides insight into a range of research that identifies the importance of providing preventative interventions for children who are demonstrating mental health challenges. Literature also highlights the use of school-wide initiatives in an effort to promote mental health wellness for all students. Considering the research findings and the research literature will be a valuable reflection of this study.

\section{Significance of Study}

Of significance to this study is the integration of mental health strategies used within a tiered system. This qualitative study will consider the gap in research literature and seek to identify how independently funded schools are currently supporting the whole child, specifically within mental health supports and initiatives. Establishing an understanding and comparison across these sectors will allow for insight toward growth in providing prevention and early intervention in mental health for elementary school-aged students in IFCES. It is anticipated that these findings, specific to Christian elementary schools, will be a catalyst for change in mental health and wellness within these schools.

\section{Theoretical Perspective}

This research will be considered in reflection of the ecological theory, with respect to the work of Urie Bronfenbrenner. This theory addresses the complexity of systems and their influence on the individual (Rosa, Tudge, 2013). The ecological model consists of layers or 


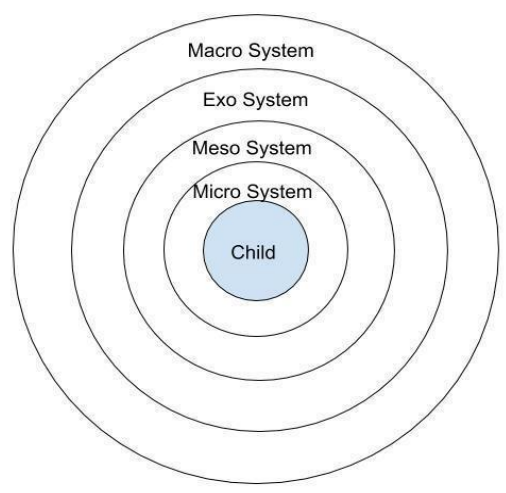

systems, as viewed in the diagram, that each incorporate various influences and developmental processes (Cross, 2017) (Gal, 2017). With the child at the heart of the diagram, the child is visually surrounded by various systems that each have an influence on the child. For the interest of this study, only the micro-, mesoand exosystems will be considered regarding their influence on the child. The micro system consists of the relationships and interactions of the child's family and immediate physical home environment (Cross, 2017). This system may also include the child's peers and close relationships that are developed at school (Brendtro, 2006). The interactions within the micro system are frequent and have been demonstrated to have great influence (Rosa, Tudge, 2013). The meso system consists of the interactions that are less influential but still impact the child. These connections could be further influenced by the relationships in the school, church and neighbourhood (Cross, 2017). The exo system refers the influence of larger systems such as school boards, local welfare agency, community helpers (Cross, 2017).

Considering the ecological theory as a lens to process how mental health initiatives and strategies are implemented within schools will allow for a deeper understanding of the complexity of this process. Schools are impacted by a range of variables, from community pressures to socio economic status, ethnic diversity, staffing characteristics and educational background, along with funding. Unique to the study is the religious component of the independently funded elementary schools. The influence of the church and Board of Directors are evident influencers of the mental health structures that are put into place in school settings in this sector. Considering these influences within the meso and exo system further draws our attention to the variation of influences within the systems as outlined by Bronfenbrenner (Barrett-Gunter et al., 2012), highlighting the value in attending to this by way of research. These systems impact the decisions made prior to implementing a mental health program and 
highlight the challenge and influence to identifying effective solutions for mental health prevention and intervention (Barrett-Gunter et al., 2012).

\section{Literature Review}

Schools are predominantly viewed as the prime location for contact with mental health supports for elementary age children (Eiraldi, Power, Schwartz, Keiffer, McCurdy, Mathen, \& Jawad, 2016). Due to the value of early intervention, establishing supports early on and serving elementary students where they are at remains a strong focus for both the educational sector and the medical sector (Sanchez, Cornacchio, Poznanski, Golik, Chou, Comer, 2018). Teachers play a pivotal role in the life of a child and have the potential to maximize the student-teacher relationship (Climie, 2015). Teachers often are the first, aside from parents, to become aware of emotional or behavioral challenges that the child may be experiencing (Sanchez et al.2018). Teachers may begin to observe these internalized and externalized behaviours, each of which may be indicators of early onset of mental health challenges (Eiraldi, et al., 2016). Supporting these students is vital to offset any potential impairments in "social functioning, suicidality, substance misuse, criminality, lower educational and occupational attainment, and lower quality of life" (Sanchez et al., 2018, P. 153). Establishing mental health supports in the school setting continues to be viewed as exceptionally advantageous for hard-to-reach populations and to have long term positive effects (Moon, Williford, Mendenhall, 2017).

Providing support in the school setting is well documented and extensively supported by research literature, however, there are challenges. Incorporating mental health supports within the school setting requires a blending of clinical and educational perspectives (Bassett-Gunter, Yessis, Manske, Stockton, 2012). Blending these perspectives has proven to take years of work among frontline staff, administrators, governments and researchers (Cook, Frye, Slemrod, Lyon, Renshaw, Zhang, 2015). Through this transition, noted barriers and challenges have been identified. One study identified a major barrier specifically around the promotion of mental health within the school (Moon et al., 2017). The barriers to promoting initiatives were reflected a lack of confidence which was reported by the teachers and support staff in the area of mental health (Moon et al. 2017) and further reflects the need for training at all levels of support to ensure an effective mental health program (Basset-Gunter, et al. 2012). A vital component of the needed training reflects an understanding of the connection between students' emotional and 
social health and their academic success (Basset-Gunter, et al. 2012). Allowing for avenues that promote emotional and social health will then translate into improved academic outcomes.

Training in the area of implementation of programs is also vital in ensuring effective rollout and outcomes (Eiraldi, McCurdy, Khanna, Mautone, Jawad, Power, Cidav, Cicia, \& Sugai, 2014). The blending of disciplines further requires a strong element of collaboration to ensure success and effective promotion of mental health strategies within the school (Moon et al. 2017). The bringing together of these two sectors will have a strong positive effect on children and youth, as they are supported within the schools should these barriers be attended to.

The tiered system of support for mental health within school settings has gained momentum and is backed by a swell of research literature (Sanchez, et al. 2018). Utilizing a "public health model of prevention where mental health needs are addressed at primary or universal (all children), secondary (at-risk children) and tertiary (children with identified mental health needs) levels" is essential (Moon, et al. 2017, p.385). Sanchez et al. identified significant findings in the meta-analysis (2018). Interventions that were carried out to all students, tier I (universal level), were identified to be experiencing small-to-medium outcomes (Sanchez et al., 2018). Most remarkable was the use of interventions to a targeted group, tier II, or use of preventative measures for a targeted group (Sanchez et al. 2018). While Sanchez et al. indicated findings with minimal effect when implemented universally within the school, it was also noted that a small effort can produce large impacts (2018). Abry, Bryce, Swanson, Bradley, Fabes \& Corwyn echo this finding, noting that the value of universal strategies (tier I) as far reaching and also have the potential to decrease stigma for the identified student, along with promoting alternate strategies for the students not yet identified as being in need of mental health supports by the teacher (2017). Research has provided evidence that the public health model of support or tiered support within the school sector has strong impacts (Cook, Frye, Slemrod, Lyon, Renshaw, Zhang, 2015). Noteworthy to include is the positive impact in providing mental health supports for children who are racially marginalized, along with the hard-to-serve students within rural communities (Moon, et al. 2017). Creating an access point for mental health supports in such a direct location allows for extensive positive repercussions that are longstanding in the future of these populations. The challenge of rolling this out into school settings 
is clearly marked; however, the gains in the student population are far-reaching and evident when considered.

In 2012, the federal government researched the use of multiple frameworks being used by provinces/territories to address the health and wellbeing of schools (Basset-Gunter, et al. 2012). Falling in line with research, the realization of the need for an identified approach was clear and led to further inquiry to establish an agreed-upon approach to school supports in the area of mental health and wellness for Canada and its provinces. Frameworks that were considered and in the end were converged together were: "School Wide Positive Behaviour Supports (SW-PBS), Social-Emotional Learning (SEL), Response to Intervention (RTI), and Systems of Care" (Bassett et al., 2012). Recently, School Mental Health Ontario established an action plan for 2019 that reflects the work that was done in creating one effective framework (School Mental Health Ontario, 2019). This plan aligns itself with the Ministry of Education and its goals in school mental health, as well as having a student-centred approach (School Mental Health Ontario, 2019). The 2019 action plan also attends to the barriers of promotion and training as identified by Moon et al., (2017), and seeks to offer support and information to improve awareness and education to those in supportive roles of students within school settings (School Mental Health Ontario, 2019). The training is slated to be geared toward evidencebased practices that specifically look at prevention and early intervention (School Mental Health Ontario, 2019). School Mental Health Ontario also maintains a strong focus on education around positive mental health for oneself along with identifying ways to access services if needed (2019).

A strong outcome of the work of School Mental Health Ontario, falls within the 2019 Action Plan diagram. See https://smh-assist.ca/wp-content/uploads/SMHO-SMSO-Action-Plan-

2019FINALEN.pdf, Appendix 1. This diagram speaks to levels of support offered within a school. Maintaining the public health framework (Moon et al., 2017), it encompasses 3 tiers as outlined in the diagram (Appendix 1, School Mental Health Ontario, 2019). This framework incorporates 3 tiers; as described below. The content of the table is taken directly from Appendix 1, School Mental Health Ontario, 2019 and seeks to offer support at several levels, intending to meet the needs of administrators, teachers, mental health counselors, students, and parents (School Mental 
Health Ontario, 2019). The goals of the action plan are significant and intend to be a direct aid for schools as they strive to implement mental health initiatives within their school community.

\begin{tabular}{|l|l|l|}
\hline Tier 1 & Tier 2 & Tier 3 \\
\hline
\end{tabular}




\begin{tabular}{|c|c|c|}
\hline $\begin{array}{l}\text { - Provide opportunities } \\
\text { for sequenced, } \\
\text { gradeappropriate } \\
\text { socialemotional } \\
\text { learning } \\
\text { - Support School } \\
\text { leaders to create and } \\
\text { sustain mentally } \\
\text { healthy schools } \\
\text { - Support educators to } \\
\text { create and sustain } \\
\text { mentally healthy } \\
\text { classrooms }\end{array}$ & $\begin{array}{l}\text { Provide } \\
\text { opportunities for } \\
\text { student-engaged, } \\
\text { sequenced, } \\
\text { gradeappropriate } \\
\text { mental health } \\
\text { learning } \\
\text { Equip educators to } \\
\text { notice and respond } \\
\text { appropriately to } \\
\text { students } \\
\text { experiencing social- } \\
\text { emotional problems } \\
\text { Provide evidence- }\end{array}$ & 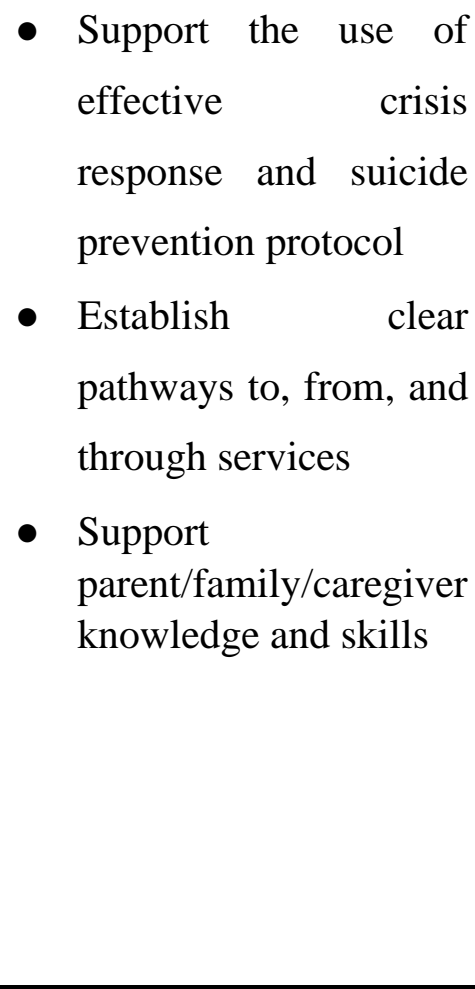 \\
\hline & $\begin{array}{l}\text { based prevention } \\
\text { and } \\
\text { intervention services } \\
\text { at school }\end{array}$ & \\
\hline $\begin{array}{l}\square \text { Equip and support } \\
\text { school system leaders } \\
\square \text { Equip and support } \\
\text { Educators }\end{array}$ & $\begin{array}{l}\square \text { Equip and Support } \\
\text { Students } \\
\square \text { Equip and support } \\
\text { school mental health } \\
\text { professionals }\end{array}$ & $\begin{array}{l}\square \text { Equip and support } \\
\text { parents and families }\end{array}$ \\
\hline
\end{tabular}




\begin{tabular}{|c|c|c|}
\hline $\begin{array}{l}>\text { Measure Progress and } \\
\text { Impact } \\
>\text { Maintain } \\
\text { Organisational } \\
\text { Conditions }\end{array}$ & $\begin{array}{l}\text { Enhance the Equity } \\
\text { Focus } \\
>\text { Equip and Support } \\
\text { School Mental Health } \\
\text { Professionals }\end{array}$ & $\begin{array}{l}\text { Equip \& Support Parents } \\
\text { and Families }\end{array}$ \\
\hline
\end{tabular}

Along with the School Mental Health Ontario Action Plan, research literature presents the benefit of the use of tiers as an approach. Various programs have also been recognized, implemented and evaluated to better understand their value and impact (Paulus, Ohmann, Popow, 2016). The variety of programs evaluated, and varying approaches found in the research literature, further exemplifies the long-standing lack of agreement in mental health supports that is prevalent among educators and mental health clinicians (Bassett-Gunter et al., 2012). The variation in approach may also be a direct reflection of the identified needs that may be viewed as unique to that school community (Bassett-Gunter et al., 2012). School communities are often complex and the solutions for one school community may be largely different from the next (Bassett-Gunter et al., 2012). Both factors draw attention to the many challenges that surround the implementation of a mental health program within a school. It is complex, requiring a wide scope of understanding, training and collaboration of all those involved (Sanchez et al., 2018). While the School Mental Health Ontario is significant, prior research continues to maintain its value by identifying potential programs and strategies for implementation within the various tiers. In 2012 the Ontario Centre of Excellence for Child and Youth Mental Health created a report that identified specific markers of success of mental health programs within schools. One marker spoke to the benefit of joining supports with community mental health agencies, highlighting their involvement in school-based services (Ontario Centre of Excellence for Child and Youth Mental Health, 2012). Drawing attention to the collaboration is a vital aspect of effective program rollout.

The report established by the Ontario Centre of Excellence for Child and Youth Mental Health brought together much-needed findings and identified beginning steps to assist Ontario 
schools in navigating the process in supporting the mental health of their students (2012). This report considered several research sources, gathering and analyzing academic and literary works (Ontario Centre of Excellence for Child and Youth Mental Health, 2012). The findings identified the three tier systems as shared and illustrated several forms of therapy that would be effective (evidence-based programs and common intervention skills). The therapies that encompass significant evidence-based practices include: multisystemic therapy, brief strategic family therapy, dialectical behaviour therapy and motivational enhancement therapy (Ontario Centre of Excellence for Child and Youth Mental Health, 2012). Most common interventions used to develop skills, as identified in this report in 2012, maintained to be "cognitive behaviour therapy and behaviour management strategies" (Ontario Centre of Excellence for Child and Youth Mental Health, 2012, p.10). These therapies focused on externalized and internalized behavioural challenges, thus seeking to support students struggling with social and emotional difficulties, aggression and violence. This is of specific interest as it provides direction on methods of mental health support that are identified as effective, this being an important backdrop to planning a mental health program.

While these strategies have been established within the tiers, research literature continued to highlight specific programs in evaluative measures. Cognitive Behaviour Therapy in school settings was closely evaluated in considering this form of therapy in groups, for internalized or externalized behaviours. More specifically, the use of modules or therapist-led sessions were reviewed extensively to determine their effect (Chiu, Langer, McLeod, Har, Drahota, Galla, Jacobs, Ifekwunigwe, \& Wood, 2013), (Eiraldi et al., 2016). Research was noted across sectors, such as educational or medical, as seen by Psychology School in Millar, Lean, Sweet, Moraes, and Nelsons article (2013). This sector evaluated the potential to increase the use of psychology staff to provide evidence-based supports (Millar et al., 2013). Assessment tools were created and/or reviewed, as seen with the "School-based Measure of Child Mental Health" (Deighton, Tymms, Vostanis, Belsky, Fonagy, Brown, Martin, Patalay, \& Wolpert, 2012). The range of research further validates the various sectors striving to identify effective supports for children in elementary schools.

A meta-analysis that is of significance follows the realization that research has been teeming in response to the noted question of how to provide mental health supports effectively in 
school settings. The analysis, completed by Paulus, Ohmann and Popow, reviews interventions that are school based (2016). Of significance is that researchers considered the tiered framework when reviewing the interventions (Tier I-III) (Paulus, Ohmann, Popow, 2016). Their findings identified several effective "behavioural, or cognitive-behavioural programs" (Paulus, Ohmann, Popow, 2016, p.1337) that demonstrated a positive impact for students experiencing emotional and behavioral challenges. Also, noteworthy is their directive to ensure a collaboration of the student's natural settings of home and school, as well as ensuring that the implementation of the programs are done as intended (Paulus, Ohmann, Popow, 2016). These directives promote effective program implementation and would suggest a stronger success rate of emotional wellbeing.

The meta-analysis completed by Sanchez et al., regards the concept that effective school based services for elementary-aged children mirrors the bringing together of school-based mental health programs (2018). The study is valuable as it recaps the prior works done specifically in the area of school-based mental health programs and quantifies the benefits of the tiered system, highlighting their strengths and evident long-term value in utilizing such a framework. The research also validates the call to mental health professionals to come alongside school communities to provide accessible support, thus decreasing significant barriers to access treatment (Sanchez et al., 2018).

Literature and research have demonstrated a clear struggle with identifying how to support children and youth effectively within the school setting. It is evident that each sector has identified a need, weighing in through research literature in an effort to determine directives that are valuable within their scope of practice. Bringing these sectors together has demonstrated the ultimate collaboration and is identified as a work in progress (Bassett-Gunter et al., 2012), (Sanchez et al., 2018), (School Mental Health Ontario, 2019). Similarly, schools have struggled to identify which service or program to access, further demonstrating the variation among school communities and their population needs (Bassett-Gunter et al., 2012). School Mental Health Ontario has made considerable strides in this valuable work by acknowledging these challenges and realizations, and further developing an effective plan. Establishing a framework of directives with an active action plan are strong wins for progress. While the various levels of 
barriers are evident for providing effective service within school settings, as noted by Sanchez et al., "child psychiatrists and other mental health professionals are wise to recognize the important role that school personnel, who are naturally in children's lives, can play in decreasing child mental health problems" (2018, p. 153). School Mental Health Ontario is working to continue the collaborative process and could be viewed as an effective resource to do so for all sectors involved in the emotional and behavioural wellbeing of children.

\section{Research Methods}

\section{Qualitative Study}

This is a qualitative study, incorporating a structured interview with a staff member of an independent Christian elementary school, over the span of five schools. This study was accomplished by utilizing a grounded theory approach (Creswell, Creswell, 2018). Applying grounded theory assists in discovering theoretical concepts and themes that develop from the gathered data via the interview with the staff (Holton, 2010). The data was obtained by inviting one staff member from five different schools who oversee the mental health program and initiatives of their school. Specifically, information was gathered around the mental health initiatives and strategies used for the students, seeking to understand how the students are supported within independently funded elementary schools. Unique to this study, the schools that were studied maintained a Christian faith-base in education. The use of a qualitative approach reflects a flexible style, allowing for a connection with the staff who are initiating the strategies and frameworks within the school.

\section{$\underline{\text { Research Questions }}$}

This study will look to discover present-day mental health strategies and interventions that are being used in independently funded Christian Elementary Schools in southern Ontario and how they compare to the tiered system, which includes the integration of mental health approaches as viewed in research literature. Considering the various levels of influence within the ecological theory, the school system has a prominent role in the area of prevention and intervention of mental health needs of their students (Bassett-Gunter et al., 2012). Taking a closer look at this sector allows for awareness by way of research literature and creates the potential to impact mental health practices. To better understand present-day mental health 
initiatives and strategies within elementary schools, this study will strive to answer these research questions:

1) How are independently funded elementary Christian schools supporting the mental health and wellbeing of their students?

2) How do these supports fall into the tiered system of support and do they take an integrated approach?

\section{Data Collection Procedures}

The sampling consisted of five schools in southern Ontario. Each school was contacted by email with information about the study and an invitation to participate. Schools which were elementary, independently funded and Christian were included in this study. As well, they were required to be within driving distance of the researcher to allow for face-to-face interviews. Upon identifying schools that fit these criteria, invitations were emailed to a total of 12 schools. This invitation (Appendix 3, Letter of Participation) was then reviewed by the administrative staff. If they chose to proceed, they then provided information regarding the study (Appendix 4, Letter of Participation, Appendix 2, Consent Form) to the Board of Directors of that specific school, who then either approved or denied any further participation. Upon approval, the researcher provided another invitation to participate to the staff (one) whose contact information was forwarded to the researcher. The potential candidate was provided information about the study along with the confidentiality form via email. If they agreed to participate, a prescheduled time was planned together for the interview. All interactions were done via email to allow for ease in declining to participate. Considerations in the area of privacy were made prior to the interviews taking place. Recommendations to use a space that allows for privacy and confidentiality were considered with the interviewee, such as accessing a room with a closed door and to allow for minimal visibility from passersby. The qualitative interview consisted of four preset open-ended questions, each question included probes. The probes were adjusted following the pilot (first) interview to further substantiate the research questions of this study. Each interview was face-to-face with one or two staff members who oversaw or facilitated the mental health program of the school. The interview style allowed for the interviewee to provide a range of information as related to the questions provided (Creswell, Creswell, 2018). The 
preset questions and time allotment of one hour allowed for the interview to remain on track, seeking out information to further the directives of the study. This style of information and data gathering is impacted by the researcher's bias, social location and reflexivity (Creswell, Creswell, 2018). Similarly, the interview setting can be viewed as intimidating for the interviewee and also has the potential to impact the data and information gathered for this study (Creswell, Creswell, 2018).

Data Recording Procedures

Recording of the data for this study took place in various ways. Brief notes were taken on the interview protocol (Appendix 5) during the interview, and the interview was audio recorded. The recorded materials will be kept for varying lengths of time as approved by the Research and Ethics Board. Audio material is kept until transcribed. Written material is kept for one year. Digital documents will be kept for four years. This information is provided for the participant on the confidentiality form and is reviewed with the participant to allow for any questions or clarification.

Data Analysis Procedures

The data analysis process began immediately following the interview. The researcher began the process of immersing themselves into the data by reflecting on the interview, noting anything surprising or consistent, and adding these findings to the field notes created during the interview. These findings may have been in reflection to the interviewee's response to questions, ease to answering questions, or due to the bulk or scarcity of a response to a question. The audio recording was then transcribed by the researcher. Following transcription, the researcher reviewed the content, and spent time reading it and considering potential themes. Using an open coding method, the data was then thoroughly considered with the support of the software NVivo (Holton, 2010). Reviewing each transcript line by line highlighted items of significance, creating initial categories (Holton, 2010). Concepts or ideas of significance that emerged from an initial category were indicated on a memo within the node. In doing this, core categories emerged such as: kids are not the same, variability of need and relationship. As more patterns emerged within the codes, theoretical concepts also began to emerge (Holton, 2010). The data was then retrieved from the interviews and categorized to further substantiate the theoretical concepts as they became apparent, adding value to their worth. The significant 
amount of data found demonstrated the value of the theoretical concepts and further supported them (Holton, 2010), as well as, lead to a better understanding of mental health for independently funded elementary Christian schools.

\section{Ethical Considerations}

Ethical considerations were considered throughout this research study. Specific attention was given to maintaining the privacy of the schools that participated. No identifying information of the school or of the interviewee was included in the content captured in this literary work. Documentation, or written content, was also considered as a way to maintain confidentiality. Pseudonyms were used in place of school names on the field notes.

Confidentiality forms were stored separately from the field notes to decrease the opportunity of cross-referencing. All written forms were kept under lock and key. Audio materials kept for the research requirements were kept under a password. The researcher also maintained confidentiality in not identifying whom the participants were when asked verbally by inquiring individuals. In the area of maintaining safety for the children of the schools, all participants were informed of the researcher's legal requirement to report any situation that may suggest a student or student population were being harmed in some way (emotional, physical, sexual).

\section{Emerging Themes}

\section{Qualitative Analysis}

In conducting a qualitative analysis of this topic, it was intended to identify and learn how independently funded Christian elementary schools are supporting their students in the area of mental health. This analysis is made up of five interviews that were taken with the staff member who oversaw the mental health initiatives and supports at the school. During the interview four main questions were asked with probes to further draw out perspectives and information. Direct quotes are used from the interview, as identified from the recording taken during the interview, with no corrections in language made. In taking a closer look at the recordings, various themes emerged, allowing for new findings and a deeper understanding of this sector.

The analysis will highlight several themes and subthemes, each reflective of the mental health representative's experience within their school environment. Each of the parties could identify initiatives and strategies that they have in place at their school to promote mental health 
and wellness, and they could recognize several areas of perceived need for further growth. Within these two areas of discussion, various themes and sub-themes developed, creating a picture of this educational sector's experience with supporting present-day mental health needs.

The interviewees consisted of individuals that were all employed on a full-time basis with the school. Their education varied; however, each of them had a degree that allowed them to teach $(4 / 5$ interviewees $)$ or to do social work ( $1 / 5$ interviewees $)$. The job description of each of the mental health support staff varied. There were administrators (two-both from the same school), a Social Worker (one), and Teachers (three). Understanding the background of the interviewees is helpful as it adds to the understanding of the themes that arose through the coding process. The content below highlighted the variability among the mental health support person within each school setting.

* I have a degree in special Ed.

* BA of Arts of Clinical Psychology, Special education

* I'm a child and youth worker, and a registered social worker

* A lot of life experience but I did my masters in behaviour management (Gr. 1/2 Teacher) My role is called Director of student services I oversee EA's, we have 9 EA's

* For me to be a classroom teacher and then to make that switchover to principal and part of an administrative team has been kind of unique situation in the sense that you work side by side colleagues and now you kind of have a chance to shape the direction and the way that things are going for the school

* I'm the executive director

* My main role is that I teach grade $1 / 2$. I also have a behaviour side to it where I deal with behaviour management throughout the school right now it is mostly primary grades.

* I'm the special ed resource teacher, but also oversee the department. We're trying to call it Student support services 


\section{Personal Investment and Passion}

In meeting with each of the interviewees, it was evident that they each carried a passion and investment to the mental health of the students within their school community. A range of points highlighted this, drawing attention to each of their unique positionings of influence. Identifying value in collaboration, the need for continued learning, distributing funds effectively, reaching kids in a relational way, and considering the shift in what it means to teach kids today. A demonstrated passion for mental health was present in each of the representatives.

* That's been amazing to develop these collaborating relationships where we trust each other where I'll make silly requests like sticker programs.... They're willing to try all these strange things, right, that come up and I think that has been a huge success.

* And now I'm sitting in rather than a guidance counselor front line, now I am in a position of leadership and distribution of resources and how do we make those things work and priority of where we need to have them take effect. I would say it has been a question we have been wrestling with more intentionally.

* ...like they just have that rapport, I think we are missing that in today's society to connect to and feel their pain. If we could make that wider and give more opportunities.

* We want to create an environment where teachers can be awesome teachers and do what they do well and put supports in place so that they don't have to choose one or the other.

* My thing is that there's a reason why that child is in my class. So, what can I do to help them feel loved. And mostly if I can sit down and talk to them, then that's it. It's so simple sometimes. Letting them see you and that you see them. Lots of the issues disappear.

\section{Kids are not the same}

A major theme that emerged within the interview findings directly accented the concept that kids are not the same. The interviewees suggest that there has been a change, that the expectation for kids to sit and listen is unrealistic. In identifying this theme, further themes 
became evident by identifiable patterns. However, spending time considering the change in the students of today, within this sector, is an important starting point, as it is the catalyst for the development of mental health initiatives. The interviewees described the changes as noted below.

- I think it's so important that we realize that kids are not the same.

* I think overall anxiety, starting at younger ages

* Definitely that there are more and more needs. And staff are looking for ways to meet those needs because there are more and more issues. Teachers have to choose between teaching and addressing either social and emotional or anxiety, mental health and when that happens, we lose the... we don't have to be in a position where our teachers have to choose.

* Behaviour had changed...Kids have no control of themselves, any self-control to sit still or to be quiet. They are always on edge. Lots of little frustrations, like I can't sharpen my pencil.

* I even think more complexity, even in the past 5 years, kids are more complex, they bring more with them to school, for a variety of reasons, their relationships are different than they used to be, kids often have a bit of an edge to themselves and so you are managing that.

People are coming with a lot more of heavy stuff, with situations at home, coming with a lot more baggage and things to worry about.

\section{Family Breakdown}

Amid this theme -kids are not the same- came several sub-themes further articulating how kids have changed. The sub-themes emerged in an array of descriptions, provided by the interviewees. One attribute that was clearly marked across all five interviewees was family breakdown.

- Family breakdown and dysfunction. Poor parenting strategies, that often go hand in hand because they are just trying to cope and manage themselves. Also, I would say some of the parenting choices and styles... we are supposed to be supporting the home but sometimes it feels like we are going against it. 
* Families are different now.

* Parents are separating.

Each school indicated that this change within the family system is happening on a more regular basis, directly impacting the wellness of the student. The mental health representative spoke of engaging and supporting students of families where the parents have separated or there is a breakdown.

Anxiety

Anxiety was the next strongest change noted by each of the interviewees, directly worded in four of five interviews. They identified that this change in the child has led to needed mental health support within the school setting.

* I'm noticing meltdowns in kindergarten...or they are anxious to go to the bathroom or they are anxious to come to class in the morning.

* I think we do have a lot of anxiety, and a lot of undiagnosed ADHD which I think it's manifesting in girls as anxiety and boys it's acting out. I think in the past it was manageable, but now it is an epidemic.

* It's anxiety, it's off the charts, there's so many kids with anxiety. Online Influence

Three interviewees identified the influence of kids being online. Each of the indications were connected to identifying the increase in anxiety in students at their school.

* Another thing that has grown, is saying nasty things online. At a lower age. Now there's group chat and so and so said that.

* They just can’t leave it at school...two girls say nasty things on their phone and the parent contacts the teacher to intervene rather than the parent calling the other parent.

* There's a lot of social challenges nowadays with media.

This sub-theme demonstrates the social challenges that can occur among children and the impact it can have, translating into anxiety and further challenges with peers.

The open coding process assisted in recognizing main concepts that highlighted specific patterns and commonalities directly connected to the children in elementary schools, specifically within this sector of Christian schools. These categories were identifiable causes of mental 
health challenges. The changes within the students were clear, bringing to light three main themes of family breakdown, anxiety and online influence. Along with these changes, with less data to support the validity of the finding but still worth noting, is the awareness of ADHD, Autism and Self-Harm as identifiable mental health needs of students requiring intervention within these school settings.

\section{Response to Mental Health}

The second main category identified in response to open coding was the response to the identified mental health challenges. A range of intervention and preventative strategies were revealed, some with strong patterns and data to support the findings. These interventions and preventions were provided in response to a need and/or to prevent challenges. Further reflection led to patterns and codes that led to greater validity.

\section{Responsive Classroom}

The mental health challenges found in the data clearly suggest the potential need to implement various supports. While this is so, there are mental health supports that are used more often within this sector. These supports range from school-wide initiatives to supports that are specific to a few students. One of the most common supports used is Responsive Classrooms. This program uses an evidence-based approach to "teaching and discipline that focuses on engaging academics, positive community, effective management, and developmental awareness" (Responsive Classroom, 2019). This strategy was identified across all five schools and is noted as a teacher-led strategy, across all grades. It was described as below:

We have devotions, we have circle time, we have responsive classroom, 8:45am classroom circles, check-in and morning meeting, everyone's voice is heard and we have a talking piece and we have devotions and the words we say and our actions and all that stuff comes out. Every classroom starts with that at this school

* Our intentionality, for example, with Responsive Classroom, one of the aspects of that would be a morning meeting and a closing circle at the end of day. I would say most of our primary and junior classes would do it daily, intermediate level - twice a week.

At the beginning, it was a little awkward for kids and staff members alike and now kids look forward to those opportunities to speak. 
* I think the responsive classroom piece...and then had realizing that there are a lot of kids in this class that could go for a whole morning without being acknowledged. They are quiet, they are good kids. A realization of how important it is that each child to be recognized by name and be given a chance to speak.

It is evident that the Responsive Classrooms program has an effective response in the school. It is described as being used intentionally, within the whole school, and allows for students to have a voice and to get things out. Responsive Classrooms has demonstrated an impact across all schools as identified by the data.

\section{Zones of Regulation}

Another sub-theme in acknowledging that kids have identifiable mental health or social challenges, is the implementation of the program Zones of Regulation within schools, via the classroom. Four out of five interviewees identified this program as an effective program to assist students with regulating their emotions. This program is a Cognitive Behavioural approach that uses a framework to teach and implement skills to support emotion regulation by

increasing independence in the area of improved emotional awareness and self-control (Zones of Regulation, 2019).

* Well Zones of Regulation, we use that and the tipping point and the flipping your lid. Those zones are posted in ***'s classroom and kids can self-regulate

* The teacher will have a quiet conversation, if you are in the high yellow, do you need to go for a walk. I often get notes from kids, so and so just needed a break, come on in and read me a story.

* I think the zones are great - but I'm not sure how good it is for; we have a boy in grade 6 and I'm not sure if it's a bit young. I'm kind of thinking Brief Solution-Focused therapy would be good for the grade 6-8. I'm hoping to do more of that.

One school used the Zones of Regulation in their classroom to improve emotional development. Other schools use it for a specific population of students who need support with emotion regulation. It was noted that this program works well for the primary school-aged students, though there was uncertainty as to its effect for the intermediate and senior students. 


\section{Classroom Structure}

Another strong finding highlighted by the interviewee was regarding how the classroom has been adjusted in response to the changes noted in students. Two classes identified creating inclusion as a priority with regard to special educational needs, thus providing the support staff in the environment of the student. It was also noted that having the additional adult (Educational Assistant EA) is beneficial, especially when they are paying attention to the dynamic of the classroom, allowing the teacher to carry on with their tasks. Collaboration was a noted side benefit from the added EA. Alongside the additional EA, an interviewee identified using learning centres to increase inclusion, this being another classroom structural adjustment in response to the mental health needs of the students.

* There's a more positive response to the availability of our student support staff that's no longer focused on withdraw, but are focused on integration and as a result, they're spending more time in classrooms

* To have paraprofessionals in the classroom has made a huge difference. And all students benefit from that, even if an EA is assigned to one or two students ...That collaboration piece alone. They see the class from such different eyes...She's there building relationship alongside of these kids. She has a different pair of eyes that can pay attention to the dynamic oppose to the teacher who has to get to the next to the next...

* And mostly if I can sit down and talk to them, then that's it. It's so simple sometimes. Letting them see you and that you see them. Lots of the issues disappear. Like I have kids with Autism. Some are diagnosed and some are in the process. So, what do you do, kick them out because they don't sit still? Or you say, go to the listening centre and I teach the lesson and then come in. You just have to change your style. 
It was recognized by two schools that the classroom and the schoolyard are both areas where social and emotional learning can take place, both to allow for mistakes and impactful learning to happen. It was highlighted that sending a student home after striking a student has less positive impact than if the student is provided tools to learn to socialize better, and that the option to 'right the wrong' has strong value. Creating a classroom with strategies to manage emotions was identified as a strong addition to support the change noted in children within these schools as identified below.

So let's give them tools, give them ways to socialize with each other and stuff too. They need to have play too. They need to have hard times in play so that they can sort it out. I have boys in the yard who fight over a soccer game. One person throws a punch. By the time they get to the office, they've talked about it, they've said why they are frustrated they've moved on... if you send them home, they aren't going to deal with any of the consequences. Let's do it here, this is the safe environment. Let's know the kids, let's give them the tools. Let's not expect them to be good anymore.

* I have a quiet space in the hall with the different signs for breathing with some choices you can make. I have quiet space at the side of the classroom. All the activities happen in the middle. We have buddy classrooms so that if you really need a break from here you can go there....If you need a break, you are welcome to leave, everyone can have a break - just tell someone.

\section{Camps on TRACKS}

Another sub-theme found within the classroom structure is the use of Camps on TRACKS. This program is peer-mediated and evidence-based, where adults teach children "to be better friends to their peers with disabilities and social challenges, ... where all children are included and are meaningful participants". (Camps on Tracks, 2019). Data was gathered from three interviewees. They identified this program as a strategy used specifically in the area of inclusion. It was explained as being a teacher-implemented strategy and was implemented at the discretion of the teacher. The interviewees spoke of it as noted below.

* Camps on Tracks, again to provide strategies to help students, help teachers support students in their interactions. 
* And so, I have 1 boy that's autistic. He's a handful, but he's lovely and all the other kids' kind of take over and soothe him and like we've done Tracks.

* The whole school has done it (Tracks) but it's primary push right now. I don't have to tell someone to sit down, someone else will whisper it over to them. It makes all the difference. And there are days when no one should talk to that child. That was a hard thing for the kids. And they'll say to me "I was going to talk to them, and I didn't" and I say that was a good choice. They're such a lovely bunch.

The tracks program is a strong sub-theme, articulating the in-class benefit as noted by one interviewee. As the results are identified by the implementor, it is clear that there is potential for the positive effect to be in response to one's sense of inclusion for students. Classroom Sessions

In several instances, the interviewee identified the need for a class or group population specific session. This category emerged in response to all five schools identifying this method of intervention. The group or class sessions were identified as a need in response to the changing behaviour of the children within their school community. A wide range of population-specific sessions was described, while highlighting the theme of classroom sessions.

* I run social skills groups with grade five and grade six right now

* They do have talks about it (using media wisely) or they'll do activities together, but I feel like it's a bandage.

* I had lunch with them over lunch for a few weeks, we would talk about the stress scale, how to bring your body back down. I met with a group of girls in grade 7 and sacred sisterhood. We had an incident of bullying in a third-grade class and we called in a therapist and she came in for a number of sessions, sent a summary home to the parents. I've had a group of students come in before school. They had a really hard time with entering school. They would write their worries down, it's entry that is really hard for kids who are anxious.

* The other student is in grade 8 and we went to the funeral and we sat in a circle. $\mathrm{L}^{* * *}$ was there, she spoke about how to come alongside someone and how to function in a class, that was powerful. 
* We had one parent pass away and I did a 6-week session, which is basically the Hospice Program. And then the following year something came up again and I did something with them again.

The session topics shared in the above examples each have a responsive nature to them. When a need arose, the teacher or mental health support staff shared this strategy as a way to promote restoration and healing.

\section{Community Supports}

In reviewing the content of the interviews, it was identified that four out of five schools accessed community supports. Again, there was a range of supports accessed and for varying reasons; however, the common theme here was initiating the contact for supports that were in the community. The interviewees identified the supports as below.

* We have Contact Niagara, that's our gateway service.

* We do refer kids, fairly quickly, I don’t want to say quickly. We have a number of our kids who are seeing counselors at Shalem or the Grimsby Life Centre.

* That's the frustrating part. Sometimes they'll meet with a counselor two times and think that it's done. Not even scratching the surface.

Another one is Woodview.... I do have a counsellor we refer to. She's a therapist and I've referred a few people to her. There's the Rock in Burlington. We are trying to branch out to other organizations because we can't do it all. I have a friend who is an art therapy,

The data identifies that the interviewee is accessing only a few community supports. However, as mentioned earlier, each school identified a capacity to access services within their community as needed.

\section{Preventative, Intentional and In Response To}

The findings also gave evidence to the use of strategies in a preventative measure or in response to a situation. Drawing awareness to the need to implement a strategy or initiative is valuable as it often led to revealing gaps and areas of needed growth within the mental health program. Prevention, intervention and reacting to were spoken of by the interviewees in various ways, often in acknowledgment that being proactive has great value. 
* Also had Camps on TRACKS come in, so I guess I lied, I did do some things. Camps on Tracks again to provide strategies to help students, help teachers support students in their interactions. We are trying to be more deliberate instead of responsive.

* It's becoming a little trickier, and our teachers would share that too...or how I can listen to your concerns in this time but how do I move that forward. We talked about mental health first aid staff training for our staff members to give them some tools that will help them directly to provide assistance in the classroom.

We're trying to work on that and like especially in the middle school. To look at curriculum to build it in and we talked about assessing all of our health curricula and being more deliberate and speaking into these things.

* To be more proactive and to build awareness into every grade. Because I do think that being responsive is not good long term. We need to get ahead of it as well as beside it and pick up the pieces behind it as well.

\section{Chapel}

Within this sector, the use of Chapel was also identified as a proactive and reactive strategy by differing schools. Three interviewees identified this as a preventative measure in its use of identifying positive character traits. Similarly, it was implemented in response to a behavioural concern that was impacting the whole school.

* We have in the past have had chapels that speak into a need. Like kids are being mean to each other or unkind and then we'll have a chapel. But we haven't been proactive we've been reactive.

* We have six character traits that we have been exploring as a school over the last two years. ... To listen to a couple of 7-8 boys and girls talk about their experiences in persevering to do homework or on a hockey team or whatever that might be...so I think a sharing of peers is an important piece. I think the more that those words become part of their vocabulary, it resonates with who they are as learners at school.

* I think Chapel, we've made a theme of empathy, kindness, we have weekly chapels and we put character traits that weren't all Christianeeze but more practical Christian living

\section{Relationship}


Within the development of the categories, the theme of relationship emerged. Among the other strategies used for children in their notable changes, it was clear that the use of relationship was a strong tool and influencer in implementing mental health and wellness initiatives across all five interviews. The use of relational practice was evident among staff, among administration and staff, among staff and students and among students and students. The content below articulates these findings further demonstrating the theme.

* From gathering all these pieces, we are starting this journey of how are we supporting our students with mental health and how are we recognizing it?

* We have devotions, we have circle time, we have responsive classroom, 8:45am classroom circles, check-in and morning meeting, everyone's voice is heard and we have a talking piece and we have devotions and the words we say and our actions and all that stuff comes out.

* I think there is also the realization that they are not in it alone. $\mathrm{K}^{* * *}$ and I will be asked to come into a classroom from time to time to help diffuse a situation. Whereas years ago they used to shut their door. Now they are coming to the staffroom at recess, not as a complaint, I'm looking for suggestions, for strategies.

* I have boys in the yard who fight over a soccer game. One person throws a punch. By the time they get to the office, they've talked about it, they've said why they are frustrated, they've moved on.

* Well when I go up to grade 3 there is usually a boy in the hallway really angry about something. He could be throwing something or whatever. My first thing is how are you? Do you need help. It's not about what did you do wrong. It's talk to me first and we will talk about your consequence after.

* Just like my work is relational, my interactions with professionals within my workplace is very relational and based on trust.

Another part is Restorative Practices, we are going to gather around this table, we are going to make it right. Kids sit knee to knee after recess if there is a breakdown in relationship. So just developing that with our staff members and passing that torch onto 
our kids so that they are able to continue and engage in the same conversation. Those are the key pieces that have really driven forward the concept of being a community of learners in the classroom/school setting.

* The other student is in grade* and we went to the funeral and we sat in a circle. $\mathrm{L}^{* *}$ was there, she spoke about how to come alongside someone and how to function in a class, that was powerful.

The use of relationship is clearly evident as seen in each of these quotes. Each school demonstrated a strong use of relational practice and spoke of it often in connection to mental health. This data exemplifies the use of relationship, demonstrating its value and importance in all levels of school function to promote wellness.

\section{Variability of Need}

Each interviewee represented a school in southern Ontario and shared their view and perspective of mental health as experienced within their school environment. Among the interviewees, there are common aspects, such as the school population is elementary, independently funded and a demonstrated Christian faith-base. Amid these similarities across the schools, the content demonstrated a wide range of perspectives, often revealing what they needed as their next important step. This pattern of revelation was often repeated several times throughout the interview and was dramatically different from that of other interviewees. Below are the themes that emerged within the interviews.

* I think a social work presence in the building that we could address those things during the day.

* That goes back I think, to the health curriculum and what we want to address at every grade. And what need we want to speak into.

- We are created to feel things so it's ok to feel things and so they are so supportive. You know, so and so is struggling, we are going to give him a break. It's not cause we don't like him or whatever. It's going really well. I guess somehow, we could get it out onto the playground, but it needs to be more. It needs to be bigger. 
* We have to be allowed to do things and we need to have the proper policies and structures in place so that we can do it well. And that was my big take away... that we need to have policies and structures so that parents understand

* They are giving us more time for things like that, behavioural or mental health issues. You can't schedule a time. We've realizing we've rooked ourselves when we are scheduling ourselves from 8:30-3:10pm. I can't help the girl who's tearing up the room. So that idea that someone might have a bit of free time.

Policy, curricula, a culture of care, hiring a social worker and having space in the day to respond to mental health needs are all substantial themes found individually within each interview. While each of these themes are tied closely to the concept of 'more could be done', it is clear that the named area of interest, as spoken of by the interviewee, was felt to prove an effective course to promote mental health and wellness within their school.

\section{Uncertainty}

The open coding process continued to reveal new findings. A unique similarity surfaced among the data, surrounding the theme of uncertainty. The interviews reflected this uncertainty in various ways. The majority (four of five) of the interviewees responded to interview question 1 with much hesitancy. They did not give a confident yes to the question: "Does your school promote mental health and wellness?", as illustrated below:

* Yeeess?!

* Yes (with hesitancy...)

* Not overall. As a program, we blanket put out every year, we don't do that. Because I'm there, I work with all of the classrooms with issues that are coming up. But I don't think that we have program per se that generally, we're going do this to promote mental health.

* It's interesting that you ask that because, just yesterday I'm working on creating a new policy, initially starting as a focus with students, but we are starting to look at this for staff as well.

This was an interesting finding, as it seemed their responses reflected their lack of understanding of the question or to the extent in which their school promoted mental health and wellness. This same lack of confidence could also be seen when describing scenarios they encountered or how 
they described other staff or themselves in various situations. The notations below articulate this.

* The other student is in grade 8 and we went to the funeral and we sat in a circle. L*** was there, she spoke about how to come alongside someone and how to function in a class, that was powerful. I was shaking after because we didn't know how to respond.

We weren't sure either.

I feel everyone is doing their professional responsibility and they are doing it really well, but it isn't enough. So it's, you know, and we've heard from the church, they have trauma, and yes we are still trying to figure this out.

* In the gr*** class there is a teacher, he doesn't have a high... doesn't see things. In the past he's had me come into the class to speak to the class about self-esteem stuff.

* They don't understand yet how it (Zones of Regulation) work in their class. It's a lot of telling them (teachers) they have to , and you have to fail and then you have to try again.

They have a real passion and desire for loving on the kids, but they don't always know the right questions to ask. Or how, I can listen to your concerns in this time but how do I move that forward.

The lack of confidence is seen through the above quotes and further identifies a level of uncertainty that impacts teachers, students and future planning and implementation of mental health initiatives.

\section{Resistance and Blockages}

Uncertainty and lack of confidence can slow change and positive momentum and is another element impacting progress. The interview content revealed the theme of resistance to the promotion and implementation of mental health and wellness within their school. Identified blockages around teaching philosophies, expectations of the student, lack of appropriate mental health curricula, parental support, and funding were gleaned from the data. This evidence is noted below:

* But there is so much more, and they could do so much more if we could understand how they are doing. A lot of my fight is that the teachers don't want to give the five minutes 
of check-in. But if you do the five minutes, you'll have the 35 min of productiveness, rather the challenge.

* That's the frustrating part. Sometimes they'll meet with a counselor two times and think that it's done. Not even scratching the surface.

* Have you made any suggestions to your boss or to your principal?

-Ya we have, it's all again funding. Well hopefully with me getting extra time away from my students then hopefully, I can wander and just be available.

It takes time. I think for some of our teachers, it's giving them permission, to perhaps get through less curriculum, in terms of the science unit or whatever, in order to deal with the life skill piece that they need. Some of them take that on really well and for others its "but I'm a teacher". So, I think there is a little bit of a struggle around that.

....and then what am I going to do? And that's a challenge to be sometimes that admissions interview is a lie. Oh ya' he'll be absolutely fine. And then the OSR shows up two weeks later and then it's that thick - wow ok, now this is a ball of wax then we anticipated.

* I'm characterizing that older mindset which we don't have as much anymore, but the teachers feel when the child hasn't reached a certain level, I think we don't always understand the mental health piece and the learning piece, even when a child is very upset, we only have 10 min to calm them down and get them back in class, because we have to be back in class, "hurry up be calm" .

* That there's so much more to school then academics anymore. I think there are a lot of teachers who still think that a kid needs to sit because you said sit.

A large amount of data from the interviews suggests that each school experiences challenges in implementation. Lack of mental health education among staff is another area identified as a challenge for the implementation and progress of supportive strategies. While the theme of blockages and resistance is strongly present, the interviewees did speak to change happening, albeit slowly. Identifying these blockages often lead into further discussion of what was going well for the school in mental health promotion. 


\section{Battling stigma}

This sub-theme of Resistance and Blockages became evident during the coding process and content analysis. Words such as myths and stigma came up for some interviewees. For others, it was described as a 'mind-set'. The data highlighted the paralyzing and slowing effect of stigma as it impacts mental health.

* Gramma and I met each Friday afternoon for $15 \mathrm{~min}$, rather than me emailing and saying your child did this. I think that was initiated by you ( $\mathrm{L}^{* * *}$ teacher) at the time, grade 2. That was initiated by myself but at one point she said, "Ach I thought you were going to tell me they weren't able to come here anymore!" That stinks when you are the parent that is embarrassed.

We have a number of our kids who are seeing counsellors at Shalem or the Grimsby Life Centre. I think there is less of a stigma attached to that when there once was. I think when we make those suggestions to parents they know it's in a place of care and love for their kids.

* So the building of a culture, that this belongs and this is normal. It doesn't mean that they all do that. We do recognize that for some people they will wonder. Is the teacher able to manage that child? ... You name it...and it's wonderful.

* To say ADHD is a thing, Depression is a thing, and not just like. Sometimes I've heard people say, if their faith grows this will go away. I've heard it from a few people. Or I don't want to label my child or I don't want to give my child meds. It's kind of like a stigma.

It's coming from teachers, and it's coming from parents. I think they're seeing it, but people don't seem to want to do anything. It's a stigma. They somehow think it's going to cost me a lot of money, it's going to change my child.

This data demonstrates the evidence of stigma, along with its impact on mental health and the continued challenge it represents. This theme led into the next incident that highlights the need for education and awareness surrounding mental health promotion and intervention. 


\section{Seeing Change}

The coding process brought to light this theme of Seeing Change. The data in this theme was often in response to the information shared around Resistance and Blockages. The challenges were noted within each of the mental health programs and articulated progress and change. Each interviewee provided examples of momentum while identifying room for more change. The interviewees did not elicit a feeling of hopelessness, but rather expressed hope for change and improvements for their school and for this sector (independently funded elementary Christian schools).

* I think there is also the realization that they are not in it alone. $\mathrm{K}^{* * *}$ and I will be asked to come into a classroom from time to time to help diffuse a situation. Whereas years ago they used to shut their door. Now they are coming to the staffroom at recess, not as a complaint, I'm looking for suggestions, for strategies. So a greater willingness to come together as colleagues, recognizing that they don't have all the answers.

We actually want to have some parent seminars, have a series of seminars... Maybe we do one on ADHD, ....on Depression.... On anxiety, ...or maybe we ... and we'd bring different people in. But the conversations have started. I already have parents who have kids with ADHD and they're ok with it. Their kids on meds and they're like we'd come and speak. And yes it's going to be a journey.

* Just to make it more of a... its more about calling it belonging and acceptance and getting everyone in that same mindset. So that's what we are working on, I'm not saying that is where we are at. I think some of our newer, younger teachers are open and on board.

* It depends on the person, I think there are a few teachers that would prefer it is all within their class. For the most part I think it is changing.

This data demonstrates the positive outlook that impacts the interviewees in a way that encourages them to continue to move forward with the implementation of mental health. Each interviewee had a sense of where they had started with implementation, where they were now and where they wanted to go. This theme articulates this reality. 


\section{Summary of Themes}

The content retrieved from the five interviews demonstrated various themes as well as identified some variability in mental health supports. Strong themes found were: Kids are Not the Same, use of Relationship, Variability of Need, Resistance and Blockages, and Seeing Change. There were marked sub-themes within the theme 'Kids Are Not the Same'. The subthemes addressed noted changes such as the prevalence of anxiety, family breakdown and the influence of kids being online. Within the theme of Kids Are Not the Same other noted subthemes of supports implemented transpired, identifying key supports as Responsive Classroom, Zones of Regulation, Classroom Structure Adjustments, and the use of Community Supports. It also became clear that the interviewee's often used language such as 'prevent, intend, intentional, or in response to' when sharing about the programs they've implemented. This drew attention to their intentionality and further identified more programs that they initiated with the intention to 'prevent, attend to, or to be in response to' a mental health need.

In the theme of Relationship, it became evident that each interviewee demonstrated relational practice in many different areas. In reflecting on all the interviews, it is clear that relational practice has a strong presence within each of the mental health programs. The Variability of Need further identified the variations among the interviews and potentially among the schools. Each interviewee had a specific need or theme of a need that they felt would be of greatest benefit for the mental health program in their school. These needs ranged and spoke to the focus of the interviewee in response to their experience within their school community. Two other strong themes that were evident were Uncertainty and Resistance and Blockages. These themes emerged across the majority of the interview content and revealed the challenges faced when implementing mental health strategies within a school. Battling Stigma was a sub-theme that was prevalent within the interview content. While several challenges were noted, all five interviewees had a strong sense that they were seeing change. This was identified throughout the content and had a marked range of where it was seen. Taking a close look at the findings brought about various themes and variations unique to the interviewee. 


\section{Discussion}

This study utilizes the interviews of elementary school staff (one staff/school, a total of five schools) of independently funded schools to reveal their view of mental health supports within their school setting. Unique to this study, is the focus on independently funded Christian schools. Little to no literature has been found in the area of mental health within IFCES, thus exemplifying the importance of this new beginning. Within this sector, a key focus on understanding mental health supports was identified, and highlighted the momentum being made. Another finding is the cross-generalization of prevention and intervention strategies as viewed within the tiered framework. These findings bring attention to the proposed theory that the IFECS maintain the same needs of mental health support within school settings as shared within the literature and the School Mental Health Ontario Action Plan 2019.

The review of literature, when considering mental health in elementary schools, shared a common finding which was the shared goal to provide effective care. This was evident among all sectors in the literature (educational and medical sectors) and in the interview data. The findings from the review of the interview content also demonstrated a range of programs and initiatives and a determination to improve mental health supports; however, this range of program implementation was not as broad as found in literature. This may have been in response to the specific population targeted for this research project. Those interviewed were administrators, teachers, special education teachers or support and a social worker, all within similar faith-base and educational focus. What was congruent was the level of interest in mental health programs and supports and sharing the vision to further improve and identify next steps. The interviewees demonstrated passion and personal investment, thus highlighting the level of interest within this school sector.

A congruent finding across literature and the interviewees spoke to the change of needs within children. Moon, Williford and Mendenhall speak to the reality of mental health challenges in children and adolescents (2017). One in five children will experience mental illness and only half of these identified children will receive effective support (Moon et al., 2017). The statistics are hard to absorb; however, the content of the interviewees echoed the reality that their students are also exhibiting mental health needs. Insights that reflected kids not being the same anymore, along with needs becoming more complex, were evidence of this change experienced in their school community. Other changes noted within the interview 
content pertained to an increase in identified anxiety and the impact of family breakdown and online influences on a student's mental health. It is clear that mental health challenges as noted in the literature demonstrate their prevalence in IFECS as well.

Literature identified the great challenge of blending the medical sector and academic sector's efforts and initiatives together and acknowledged the need for collaboration (BarrettGunter, 2012). Moon et al. articulated how this blending led to the realization that school staff were left feeling a lack of confidence in response to the adjusted expectations and to the changes in their role as teachers (2017). The lack of confidence was a similar theme that arose from the interview content. Upon reflecting on the responses from the interviewees, there was a notable lack of confidence that was articulated in the lack of mental health programs identified, or lack of knowing how to respond when supporting children in need. With the identification of this theme and the review of literature, there came the realization that the theme of 'Uncertainty' was symptomatic to the need for more training and awareness among school staff (Moon et al., 2017).

Another notable challenge identified by the interviewees was the experience of resistance or blockages to further the success of implementing mental health programs in their school community. This ranged from funding, to parental involvement, to teacher philosophies. These challenges were notably found in literature as well, and were address by providing supports for parents, a funding boost into School Mental Health Ontario Action Plan to assist with training and funneling out information and resources in an anticipated efficient manner (School Mental Health Ontario, 2019). These similarities are marked among the dual context of IFCES and the school communities found in the literature.

Research literature continues to mark the value of using the tiered levels of mental health support as a framework (Cook, Frye, Slemrod, Lyon, Renshaw, Zhang, 2015). Being viewed as an effective system to "organize and deliver a continuum of school mental health services" (Cook et al., 2015, p.167), it is a strong finding to see School Mental Health Ontario supporting this directive. Of the interviewee content, only one school spoke of using this framework without prompt or information surrounding the framework. One school identified that the materials and resources from School Mental Health Ontario, proved to be helpful and become a catalyst for identifying the need to further policy development. While the tiered system is proving the test of time (Sanchez, 2018), it is clear that this form of a framework has not been Mental Health in Independently Funded Elementary Schools 
used specifically within IFCES. However, through reviewing the interview content, it is evident that supports are being offered by the school community and support personnel would perhaps fit into the various tiers within the framework.

Tier I is notable for the universal, prevention points of mental health supports (Eiraldi, McCurdy, Khanna, Mautone, Jawad, Power, Cidav, Cacia \& Sugai, 2014). While it is identified that this tier has some impact, the long-term effects are unknown and are perceived to have an extensive ripple effect (Sanchez, 2018). It is clear that the interviewees and the school communities they are supporting see great value in preventative supports and initiatives. The program that was identified across all 5 schools was Responsive Classrooms. This program seeks to promote social emotional learning in the classroom. All interviewees identified it as beneficial and part of their mental health strategies that take place at their school. As well, the use of Chapel, to promote appropriate social emotional learning, is used across the schools. Growth Mindset is another program used within a couple of the schools as a preventative measure within their mental health strategies. While the schools didn't articulate the use of these programs as targeting tier I activities, interview content did highlight initiatives and strategies, building on social emotional learning.

As articulated in the research literature, tier II intervention seeks to provide support to students who would benefit from early intervention or mental health support (Ontario Centre of Excellence for Child and Youth Mental Health, 2012). The research literature also speaks to school settings incorporating mental health professionals within their staffing make-up to provide tier II and tier III supports (School Mental Health Ontario, 2019). As previously defined, tier III supports are provided to students who require crisis supports and/or require further direction for referrals to community services that provide more intensive supports such as therapy and/or parent/caregiver supports (School Mental Health Ontario, 2019). The interviewee content did articulate responses to similar situations they encountered within their school community; however, they did not frame it as a response to the tier system process. Each school had a designated mental health staff member who was called on to support students who required mental health supports, an essential part of tier II supports. The interviewee's identified a range in qualifications of the mental health support person, extending from an administrative role, to a teacher, to a social worker. Of the five schools, two mental health support people were of a social work background, one being part of the college of social workers. All the tier II activities Mental Health in Independently Funded Elementary Schools 
that the interviewee spoke of were in response to an identified need of a student as it was observed in the school. When possible, the mental health support staff would implement individual care, a group session or a program to address the need and/or request support from a community agency to fill the need. Agencies were identified as a resource for this level of need (tier III), as well as, established processes should crisis arise requiring further support for a student or family that is outside of the staff's scope of practice. While some of the schools were able to identify the process they followed when referring to community supports, it was evident that the extent of this process was limited. Reflecting on the research literature and the content from the interviews, it is clear that the school communities of independently funded elementary schools follow some of the tiered processes of tier II and III by way of offering mental health intervention and there are evident areas of needed growth.

The Ecological Systems Theory articulates the complexity of the systems that impact the development of the whole child, including their mental health (Brendtro, 2006). Within the systems, the micro system demonstrates strong influence of family, home and siblings (Cross, 2017). The next level of influence outside of the family and peers consists of the influence of school, neighbourhood and church (Cross, 2017). The complexity involved in the influences of a child was further demonstrated by way of variation of mental health programs and approaches used within the school sector as identified within the research literature (Bassett-Gunter, 2012). This was congruent in the content reviewed from the interviewees within the independent Christian school population. Both groupings demonstrated varied perspectives of mental health program application and supports that were made available. Within the micro system, influences of program implementation were often connected to the individual staff member's professional lens by which they were viewing the child and/or the problem at hand. Within the research literature, the range of programs and strategies studied, verified the impact of one's professional lens and their perspective of necessary support (Paulus, Ohmann, Popow, 2016). The meso system drew attention to the influence of the church within the IFCES. Chapel is an example of this influence as it was identified as being used a preventative measure, as well as resource for school wide intervention. Another area of influence within the meso system is the community in which the school was located. The varying supports and directives for mental health programs implemented can be linked to the needs of the community (Bassett-Gunter et al., 2012). This was a systemic influence, as found within the research literature. This finding was not as Mental Health in Independently Funded Elementary Schools 
strongly observed in the interviewee content and could have been due to the lack of inquiry in the interview questions within this specific area. Within the exo system, the Board of Directors offers a unique system of influence within the IFCES. It is unique in that this group is made up of parents of the community in which the school is located. As well, the members are faithbased and are the governing body for the school. Each IFCES has their own Board of Directors and this can create a wide range of variation in implementation and approval of mental health supports and/or staffing compliments. Within the research literature, the governing body of influence is the provincial and federal governments, leaving each school to follow the directives and recommendations as presented by these groups (Bassett-Gunter et al., 2012). This is a marked variation of influence. The complexity, as observed through the Ecological Systems Theory, highlights similarities and differences across both sectors, while noting the many layers of influence unique to each school and then to each child.

Addressing the mental health needs of children during their elementary school years has lasting positive impacts and is a consistent finding within the research literature (Abry, Bryce, Swanson, Bradley, Fabes, \& Corwyn, 2017), (Bassett-Gunter et al., 2012),(School Mental Health Ontario, 2019). This sentiment was shared among the interviewees via anecdotal experiences. The interviewees shared stories of students being calmer in class, the use of various strategies to maintain positive behaviour and academic outcomes, along with grateful parents and students. These noted successes validate the research findings of the great value of using schools as a portal to emotional health and wellbeing.

The need for collaboration between the educational sector and the medical sector is very real. As identified in research, it has taken several years to establish the latest 2019 Action Plan as derived by the School Mental Health Ontario (School Mental Health Ontario, 2019).

Research literature has demonstrated this tension that is acknowledged between the two sectors, thus bringing to light the real need for collaboration (Bassett-Gunter et al., 2012). This is true for the IFECS sector as well. The interview content noted potential resistance among fellow staff in implementing mental health strategies or initiatives, as well as identifying only a group of teachers that implement mental health initiatives. Collaboration is viewed, as shared by the interviewees, as being a valuable part in the implementation of mental health supports in these schools, as well. Another aspect that is a unique finding within the concept of collaboration is 
'buy-in'. It can take time for teachers to fully participate in mental health initiatives, the same can be true for administration and leadership of a school (Gal, 2017). For this project, five out of twelve schools agreed to participate in the study, a rate of $40 \%$ of acceptance to participation. There may be multiple reasons for not participating, some of the invitations replied with comments that they don't have a mental health plan as of yet, and others did not provide a response. It is important and interesting to note this finding, especially in the area of collaboration. For a school to be effective on all levels, there must be collaboration.

\section{Conclusion}

This study aimed to identify the mental health strategies that are being implemented within independently funded Christian elementary schools to establish a base of research literature. The implication of the unique organizational structure of independently funded Christian schools also piqued the interest of the researcher, as well as, simply being motivated out of professional interest. This curiosity led the researcher to utilize a qualitative approach to gain a better understanding of Christian elementary schools. The qualitative approach highlighted many themes and demonstrated a congruence between the experiences of mental health initiatives found within research and the initiatives found within the content obtained by the interviewees of independently funded Christian elementary schools. There are notable similarities that suggest that the experience within both school sectors (within research literature and IFCES of southern Ontario) have common experiences in the area of mental health program implementation. The range in programs may be due to a various systemic influence, as noted in Bronfenbrenner's Ecological Theory and model. It is clear that there are common threads that allow for a possible universal framework that may become an effective implementation tool of mental health strategies and initiatives within the public sector schools and independently funded Christian elementary schools in Ontario.

Significant to the study is the consideration of the tier system as a framework for mental health supports in elementary schools. Reviewing this system led to the findings of the School Mental Health Ontario Action Plan. The tiered system is a strong point of the literature, as it verified much of the research pertaining to its use within a 10-year span. Social emotional learning styles, problem-based interventions and evidence-based methods were incorporated within the tiered system during this time span. Understanding the coming-together of the 
research to develop this framework for schools in Ontario, is a strong resource for elementary schools of today.

\section{Recommendations}

It is recommended that independently funded Christian elementary schools strongly consider using the School Mental Health Ontario Action Plan 2019 framework as a base of understanding for their schools' mental health organizational strategy. Making decisions in response to and reflecting on the tiered system will allow for increased effectiveness in mental health initiatives, strategies and overall care of the students. Using this framework as the lens to filter mental health supports would be a valuable tool for each administrative team.

Highlighted in both the research literature and the findings from the interviewees is the need for a strong element of collaboration with all school staff and mental health support staff. Having a team approach that includes reflection on service and supports as a group will directly increase 'buy-in' and propel the success of the mental health program. While this promotes awareness, it will also allow for teachable moments among staff and lead to identifying areas of needed training and next steps of implementation.

Collaborating among community mental health support is also a vital part of effective support service for students and families of the school community. Understanding the community and services as they are available is essential, to allow for ease of support should the school not be able to support the level of intervention needed for a student.

It is clear that the IFCES are in a position to develop a school mental health plan. The interviewees identified challenges and successes and, most importantly, a desire to make improvements. Also, of interest is the interviewees' ability to identify where they felt these improvements should be made. Reflecting upon the tiered system as established in the School Mental Health Action Plan 2019 will be essential to ensure that the resources of time, energy and finances are allocated to an effective aspect of the plan.

It would be beneficial to better understand if the mental health support staff of the schools who participated in the study, follow a specific mental health framework. Questions were asked in an indirect manner to address this; however, the interviewer did not overtly ask. The findings could have benefited from having an answer to this question specifically. Future recommendations for the study would be to offer mental health program planning support to schools to begin the reflection and planning necessary for their mental health program. From 
this point, it would be valuable to connect with schools following the implementation of their plan within a five-year window and obtain an understanding of the programs and staffing structures they are implementing. Understanding the school structure and the challenges and successes of implementing the framework, as provided by School Mental Health Ontario Action Plan 2019, would also pose a tremendous benefit for further growth.

\section{Limitations}

This study consisted of interviewing only five individuals (who implement the mental health programs at their schools), thus receiving a glimpse of mental health programs within five different schools. These schools were all within driving distance of the researcher and so diversity (ethnically and socio-economically) of schools is quite limited and does not reflect a full scope across all of Ontario. The study only included schools that were elementary and provided a Christian-based education and thus sought to gather information about a specific population that supported an independent funding model. 


\section{Appendix 1}

SCHOOL MENTAL HEALTH ONTARIO

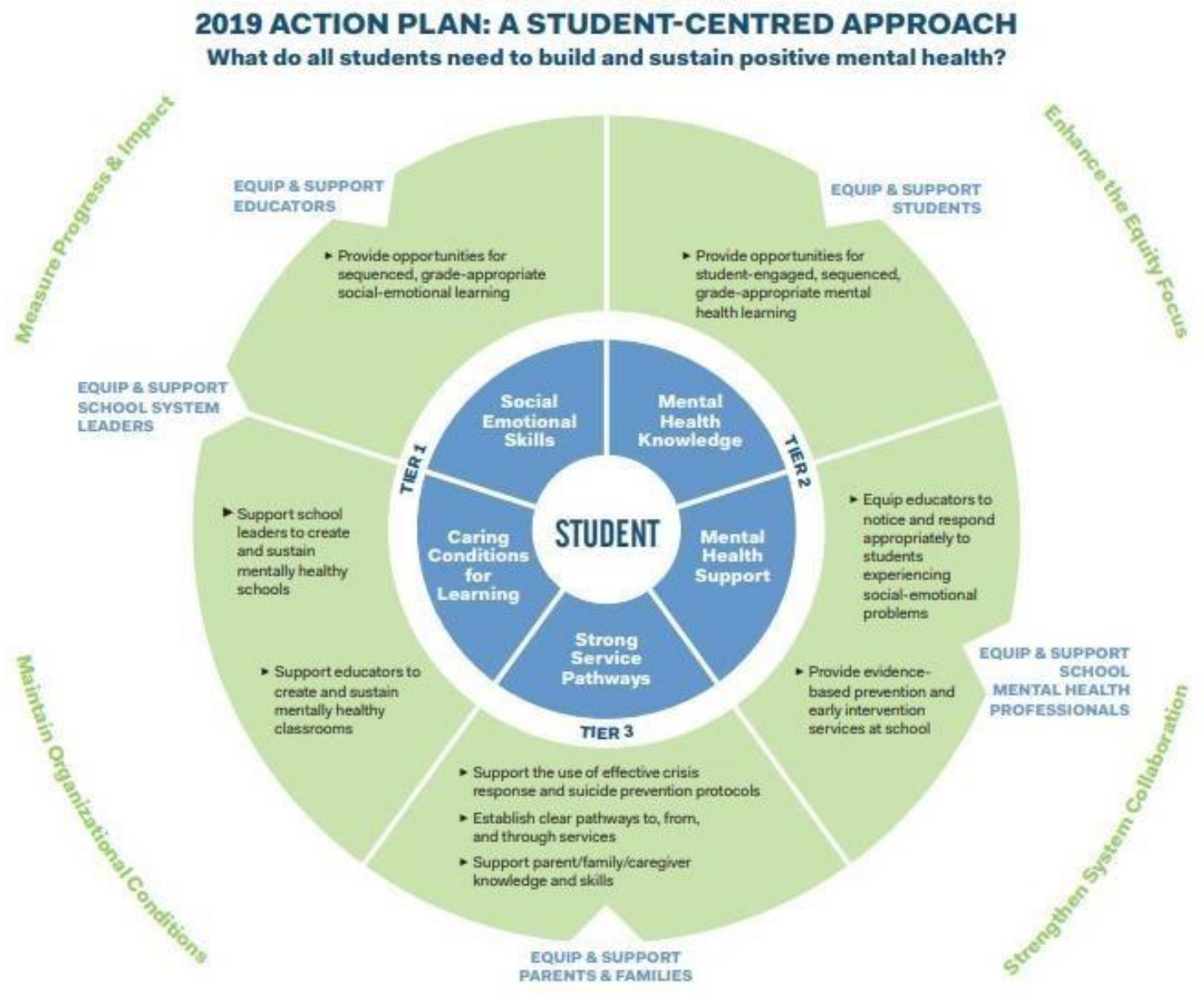

Retrieved from: https://smh-assist.ca/blog/smho-action-plan/ 


\section{Ryerson} University

\section{Ryerson University Consent Agreement}

You are being invited to participate in a research study (2019-170). Please read this consent form so that you understand what your participation will involve. Before you consent to participate, please ask any questions to be sure you understand what your participation will involve.

\section{TITLE OF STUDY:}

Identifying Mental Health Initiatives within Independently Funded Elementary Christian Schools

INVESTIGATORS: This research study is being conducted by Marge Kloet (Principal Investigator) and Judy Finlay (Supervisor) from the School of Child and Youth Care at Ryerson University. This project is being conducted as part of my graduate studies for the partial completion of my master's degree.

It is hoped that this information will be used to provide future support to independently funded elementary Christian schools by way of providing a base of information around mental health resources. This information could be used to provide expertise and support for schools by way of consultation.

If you have any questions or concerns about the research, please feel free to contact Marge Kloet mkloet@ryerson.ca,

PURPOSE OF THE STUDY: This study is designed to gather information on how independently funded elementary Christian schools are providing mental health support for their students. Five - six Christian elementary schools in southern Ontario will be contacted, interviewing one staff member from each school, in an effort to gather information on mental health programs and initiatives. It is hoped that information surrounding mental health strategies and initiatives will be established. This project is being conducted as part of my graduate studies for the partial completion of my Master's degree.

\section{What Participation Means:}

Participating in this study requires the following:

1. Receive permission to participate in the study from the Board of Directors.

2. Identify who/who could be a potential interviewee by identifying the staff member who is directly involved in the mental health initiatives within your school. Extend the invitation to participate and provide the researcher's contact information, Request for Permission letter, and Letter of Consent for added information for the potential participant.

3. Upon contact with the researcher 
a. The Letter of Permission and the Letter of Consent form for the interviewee will be reviewed to determine willingness to participate.

b. Upon agreement to participate, identify a time and place to participate in an interview, either by phone or in person, with Marge Kloet.

c. Interviews in person will take place at the address of the school interviewee in a location that has privacy, including a door, with little to no visibility to the passerby.

d. The interview will take approximately 1 hour in length

e. The interview will be recorded with an audio recording device.

f. The interview will explore strategies and initiatives that are presently being used, and will include questions such as how does your school define mental health, how did the need for supports become identified, and what are any challenges and successes experienced.

g. Contact information, such as school address, interviewee contact name, school phone number will be kept for reference and future contact.

h. Research findings will be shared with the participants following the completion of the study by accessing the Ryerson Digital Depository https://digital.library.ryerson.ca/.

\section{What are the Potential Benefits:}

The interviewee may discover personal benefits such that they have the opportunity to selfreflect on their field, allowing for self-reflection of mental health strategies. This may deepen their understanding and allow for a more reflective practice as they support students and their school with mental health strategies.

Benefits of participating in this study lie within Independently Funded Elementary Christian School sector. This study will establish a base of information on mental health initiatives and strategies that can be used as a resource for Independently Funded Elementary Christian Schools in Ontario. This study is the first of its kind and may become a catalyst for future research projects that could improve mental health supports within this sector.

\section{What are the Potential Risks to you as a Participant:}

Participating in this research project will create little to no risk for the interviewee beyond the normal risks involved with daily work. There is minimal risk in the area of social and group risk such that there is potential for loss of privacy of information or negative association of this specific school sector. There is legal risk such that the interviewer is bound by the Child and Family Services act and may be required to report any understanding of harm or threats of harm to a child or youth.

\section{Confidentiality:}


The interview can take place in the location of the interviewee's choice. It is recommended that a room be used that allows for privacy, both auditorily and visually, to maintain a high level of confidentiality.

The information received during the interview will not identify the participant in the report. The initiatives and strategies identified will be collaborated in a way that does not allow for identifying information of the participant or the school in which the initiatives and strategies are being used. Participant Interviews will be assigned a pseudonym for reference to ensure the confidentiality of the participant and of the school.

The findings will be gathered and reviewed to establish a base of information of strategies and initiatives. The final document will provide information around strategies and initiatives, and, will not identify/name the school participants.

Schools will be identified as being located in southern Ontario. Signed Letter of Consent will be kept in a locked cabinet at the residence of the interviewer, hand written interview materials will be kept in a separate locked cabinet with pseudonym identifiers in an effort to maintain confidentiality.

Paper documentation, consent forms and written interview response data, will be kept for 1 year in separate locked environments. Electronic information will be kept for four years, requiring a password for access and remain within the interviewers Ryerson Google Docs account. Audio information will be destroyed once transcribed into a Google document (approx.3 months).

Following these timelines, the information will be destroyed and/or deleted.

Duty to Report: In the event that a child or youth is being harmed or there is a threat of being harmed, the Interviewee has the duty to report such learnings to the Children's Aid Society as instructed by the Child and Family Services Act.

Incentives for Participation: Participant will not be paid to participate in this study.

Costs to Participation: There are no costs to the participant for taking part in this study.

\section{Compensation for Injury:}

By agreeing to participate in this research, you are not giving up or waiving any legal right in the event that you are harmed during the research.

\section{Voluntary Participation and Withdrawal:}

Participation in this study is completely voluntary. You can choose whether to be in this study or not. In the event that you know or know of the researcher, you are able to choose to withdraw or participate at any time. This choice will not influence future relations with Ryerson University or the investigators Marge Kloet, or Judy Finlay involved in the research.

If any question makes you uncomfortable, you can skip that question. You may stop participating at any time. If you choose to stop participating, you may also choose to not have your data included in or withdrawn from the study. Your choice of whether or not to participate 
will not influence your future relations with Ryerson University or the investigators Marge Kloet, or Judy Finlay involved in the research.

\section{Future Use of Information from Study:}

The information gathered in this study may be used for purposes of conferences, information sharing sessions, informational materials, and promotional materials.

\section{Questions about the Study:}

If you have any questions about the research now, please ask. If you have questions later about the research, you may contact:

Primary Investigator

Marge Kloet CYC cert.

Interviewer

mkloet@ryerson.ca
Research Supervisor

Judy Finlay PhD

Graduate Program Director; Associate Professor 416-979-5000, ext. 4809

jfinlay@ryerson.ca

This study has been reviewed by the Ryerson University Research Ethics Board. If you have questions regarding your rights as a participant in this study please contact:

Research Ethics Board

c/o Office of the Vice President, Research and Innovation

Ryerson University

350 Victoria Street

Toronto, ON M5B 2K3 416-979-5042 rebchair@ryerson.ca 


\section{Ryerson University}

$\underline{\text { Identifying Mental Health Initiatives within Independently Funded Elementary Christian Schools }}$

\section{CONFIRMATION OF AGREEMENT}

Your signature below indicates that you have read the information in this agreement and have had a chance to ask any questions you have about the study. Your signature also indicates that you agree to participate in the study and have been told that you can change your mind and withdraw your consent to participate at any time. You have been given a copy of this agreement. You have been told that by signing this consent agreement you are not giving up any of your legal rights.

Interview Code

School

City School Resides

Name of Participant (please print)

Signature of Participant

Date

I agree to be [audio recorded] for the purposes of this study. I understand how these recordings will be stored and destroyed.

Signature of Participant

Date

${ }^{*}$ Consent form subject to change as this project is under review of Research and Ethics Board.

\section{Appendix $3 \quad$ Request for Participation Letter}




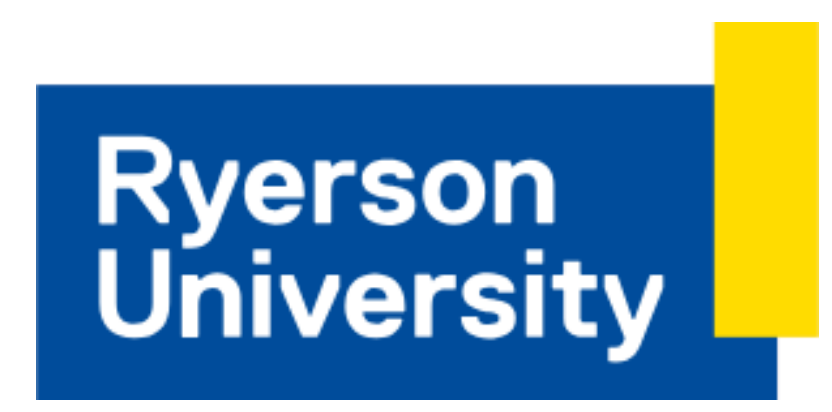

350 Victoria St, Toronto, ON M5B 2K3

March 28, 2019 Hello, My name is Marge Kloet. I am a student at Ryerson University in the School of Child and Youth Care. I am contacting you to see if you might be interested in participating in a research study. This project is being conducted as part of my graduate studies for the partial completion of my Master's degree and my supervisor's name is Judy Finlay.

The focus of the research is to gather information of mental health strategies and initiatives that are being used within Independently Funded Elementary Christian Schools in Ontario. It is hoped that this information can then be used by schools, at their discretion and depending on their needs, to support the mental health needs of their students in a positive way.

To participate, there are a few key points to consider and that require your attention.

- Your school will need to be an Independently Funded Christian Elementary School

- Permission to participate will be required by the Board of Directors as well as the Principal of the school. Please forward this letter to both parties (Board of Directors and Principal) along with the letter of consent to review.

- One staff member who is directly involved in the mental health initiatives will be invited, by the principal, to be a participant in an interview with myself. This interview would happen in person or by phone. The interview is anticipated to take approximately 1 hour. In the event that the interviewee knows or is known to the researcher, they will be reminded of the voluntary nature of the interview and of their choice to participate. This choice will not influence future relations with Ryerson University or the investigators Marge Kloet, or Judy Finlay involved in the research.

- This research project is in the process of being reviewed and approved by the Ryerson University Research Ethics Board.

If you are interested in more information about the study or would like to volunteer, please reply to this email.

Sincerely, Marge

Kloet

mkloet@ryerson.c

a Appendix 4 - 


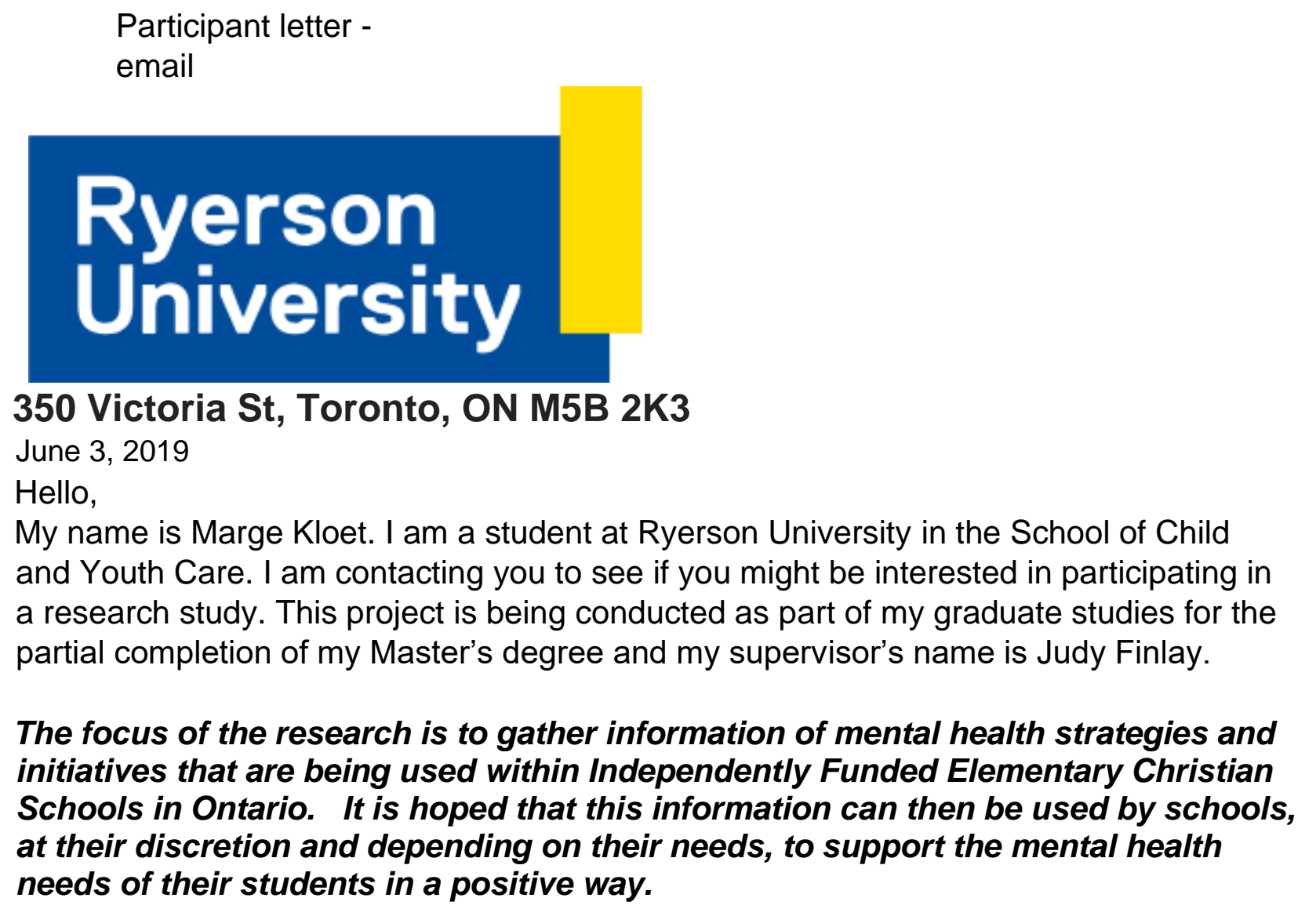

To participate, there are a few key points to consider and that require your attention.

- Your school will need to be an Independently Funded Christian Elementary School

- Permission to participate will be required by the Board of Directors before we plan a time for the interview.

- You are directly involved in the mental health initiatives of your school and have been invited by the principal, to be a participant in an interview with myself. This interview would happen in person or by phone. The interview is anticipated to take approximately 1 hour. There will be a total of 5-6 schools participating with 1 interviewee from each school. It is suggested that the interview take place in a space that allows for visual and auditory privacy, such that the interview room includes a closable door.

- In the event that you, the interviewee, knows or is known to the researcher (Marge Kloet), they will be reminded of the voluntary nature of the interview and of their choice to participate. This choice will not influence future relations with Ryerson University or the investigators Marge Kloet, or Judy Finlay involved in the research.

If you would like to volunteer by participating in the interview, please reply to this email. Sincerely, Marge Kloet mkloet@ryerson.ca 
Ryerson University

\section{Questionnaire for School Personnel 2019-170 Researcher Copy}

\author{
Introduction of Interviewer
}

My name is Marge Kloet. I am presently in the Masters

program

within the School of Child and Youth Care. This project is being conducted as part of my graduate studies for the partial completion of my Master's degree. I am a Guidance Counsellor at Providence Christian School and have taken a personal interest in furthering the mental health supports within Independently Funded Christian Elementary Schools. My interest lies in providing early intervention and emotional health education in an effort to better prepare children during times of stress and adversity. My interest lies closely with children of whom have a predisposition to mental health challenges and my genuine desire to be an active part in offering effective support and early intervention.

\section{Purpose of Interview}

The intent of this interview is to understand the mental health initiatives and strategies that are being used within your school. The interview is intended to be with one staff member from the school who implements or oversees the mental health program within the school. In this, I hope to gain an understanding of how your school defines mental health, what drew you to see the need for mental health supports, how you are meeting these needs, and what challenges or successes you identified.

The value of this research resides in the context of an independently funded school. This study is limiting the context to Independently Funded Christian Elementary Schools (IFCES) in Ontario and is seeking to identify the range of mental health support implemented. In identifying these strategies and initiatives, other schools within this context may identify that the findings may assist their school initiatives. Also unique to this study, is that it will provide research literature that has not been previously established. This study may then lead to future research that can further mental health support in IFCES. 
Inform of:

$\square$ Participation in this interview is voluntary. You may withdraw from participating at any time and you may determine if you would like your information to remain within the study or if you would like the information to be withdrawn. In the event that you know or are known to the researcher, you may choose to withdraw or participate at any time. This choice will not influence future relations with Ryerson University or the investigators Marge Kloet, or Judy Finlay involved in the research.

$\square$ The interview will be approximately 1 hour in length. There are a total of 5-6 participants, 1 from each school.

$\square$ Risk/Confidentiality: There is minimal risk to participate in the area of social and group risk such that there is potential for loss of privacy of information or negative association of this specific school sector. There is legal risk such that the interviewer is bound by the Child and Family Services act and may be required to report any understanding of harm or threats of harm to a child or youth. This would require that confidentiality be broken to maintain the safety of the child or youth.

Date:

Interview Code:

Interview recorded: Yes No

Interviewee Demographics:

What is your role and experience in the school? How long have you been in this role? What is your background?

1. Do you promote mental health and wellness in your school?

a. Probe: How do you define mental health and wellness?

b. Probe: In what ways is mental health and wellness promoted in your school?

c. Probe: Would you change anything? How?

2. What are you seeing in your school that suggests mental health and wellness is important to address in your school?

a. Probe: How has this come to your attention?

b. Probe: Who makes the referral?

3. How are you addressing it (mental health needs)?

a. Probe: What programs or strategies have you initiated

i. Do you have school wide initiatives?

ii. Do you have specific groups are seeking to support? Why? How? 
4. What have you learned from incorporating mental health initiatives and strategies?

a. Probe: What were the challenges you encountered?

b. Probe: What were the success you encountered?

i. What did you feel was successful?

ii. Did you receive parent feedback? What was it?

iii. Did you receive Teacher feedback? What was it?

1. pros/cons - why? (school culture, promotional strategy)

Appendix 6 
Ryerson University

\section{Questionnaire for School Personnel 2019-170}

Introduction of Interviewer

My name is Marge Kloet. I am presently in the Masters program within the School of Child and Youth Care. This project is being conducted as part of my graduate studies for the partial completion of my Master's degree. I am a Guidance Counsellor at Providence Christian School and have taken a personal interest in furthering the mental health supports within Independently Funded Christian Elementary Schools. My interest lies in providing early intervention and emotional health education in an effort to better prepare children during times of stress and adversity. My interest lies closely with children of whom have a predisposition to mental health challenges and my genuine desire to be an active part in offering effective support and early intervention.

\section{Purpose of Interview}

The intent of this interview is to understand the mental health initiatives and strategies that are being used within your school. The interview is intended to be with one staff member from the school who implements or oversees the mental health program within the school. In this, I hope to gain an understanding of how your school defines mental health, what drew you to see the need for mental health supports, how you are meeting these needs, and what challenges or successes you identified.

The value of this research resides in the context of an independently funded school. This study is limiting the context to Independently Funded Christian Elementary Schools (IFCES) in Ontario and is seeking to identify the range of mental health support implemented. In identifying these strategies and initiatives, other schools within this context may identify that the findings may assist their school initiatives. Also unique to this study, is that it will provide research literature that has not been previously established. This study may then lead to future research that can further mental health support in IFCES. 
Inform of:

$\square$ Participation in this interview is voluntary. You may withdraw from participating at any time and you may determine if you would like your information to remain within the study or if you would like the information to be withdrawn. In the event that you know or are known to the researcher, you may choose to withdraw or participate at any time. This choice will not influence future relations with Ryerson University or the investigators Marge Kloet, or Judy Finlay involved in the research.

$\square$ The interview will be approximately 1 hour in length. There are a total of 5-6 participants, 1 from each school.

$\square$ Risk/Confidentiality: There is minimal risk to participate in the area of social and group risk such that there is potential for loss of privacy of information or negative association of this specific school sector. There is legal risk such that the interviewer is bound by the Child and Family Services act and may be required to report any understanding of harm or threats of harm to a child or youth. This would require that confidentiality be broken to maintain the safety of the child or youth. 
Date:

Interview Code:

Interview recorded: Yes No

Interviewee:

What is your role and experience in the school?

1. Do you promote mental health and wellness in your school?

2. What are you seeing in your school that suggests mental health and wellness is important to address in your school?

3. How are you addressing it (mental health needs)?

4. What have you learned from incorporating mental health initiatives and strategies?

\section{Appendix 7}




\section{Ryerson
University \\ 350 Victoria St, Toronto, ON M5B 2K3}

\section{Resources for Schools}

\section{Shalem Mental Health Network}

This organization is a faith-based, Ontario-wide network that provides responsive and preventive mental health support to individuals, families, and communities. These support services seek to restore hope.

875 Main St E, Hamilton, ON L8M 1M2 https://shalemnetwork.org/

(905) 528-0353

\section{Children's Aid Society}

This organization is committed to the safety, protection, and well-being of children and the strengthening of families, while valuing diversity and promoting equity.

\section{https://www.hamiltoncas.com/}

(905) 522-1121

\section{Kids Help Phone}

Kids Help Phone is Canada's only 24/7, national support service. They offer professional counselling, information and referrals and volunteer-led, text-based support to young people in both English and French.

https://kidshelpphone.ca/ tel:1-800-668-6868 


\section{References}

Abry, T., Bryce, C., Swanson, J., Bradley, R., Fabes, R., Corwyn, R. (2017). Classroom-Level Adversity: Associations With Children's Internalizing and Externalizing Behaviours Across Elementary School. American Psychological Association, 53(3), 497-510. Adams, P. (2006). Exploring Social Constructivism: Theories and Practicalities. Education, $\quad 34(3)$, 3-11.

Bassett-Gunter, R., Yessis, J, \& Manske, S., Stockton, L. (2012). Healthy School Communities Concept Paper. Ottawa, Ontario: Physical and Health Education Canada.

Available at: http://www phecanada.ca/programs/health-promoting$\underline{\text { schools/concept-paper }}$

Brendtro, L. (2006). The Vision of Urie Bronfenbrenner: Adults Who Are Crazy About Kids. Reclaiming Children and Youth, 15(3), pp. 162-166.

Brendtro, L., Brokenleg, M., Van Bockern, S. (2014). Environments Where Children Thrive: The Circle of Courage Model. Reclaiming Children and Youth, 23(3), 10-15.

Camps on TRACKS. (2019). Camp for Everyone. Retrieved from: http://campsontracks.com/ Center for Injury Prevention and Control, Division of Violence Prevention. (2019). The Social-Ecological Model: A Framework for Prevention. Retrieved from https://www.cdc.gov/violenceprevention/publichealthissue/social-ecologicalmodel.html Climie, E. Canadian Children's Mental Health: Building Capacity in School-Based Interventions. Hammill Institute on Disabilities, 51(2), 122-125.

Cook, C., Frye, M., Slemrod, T., Lyon, A., Renshaw, T., \& Zhang, Y. 2015. An Integrated Approach to Universal Prevention: Independent and Combined Effects of PBIS and SEL on Youth's Mental Health. School Psychology Quarterly, 30(2), 166-1383.

Creswell, J., Creswell, J.D. (2018). Research Design Qualitative, Quantitative, and Mixed Methods Approaches. Sage Publishing. Los Angeles, U.S.A. (book)

Cross, W. (2017). Ecological Factors in Human Development. Child Development, 88(3), 767-769.

Deighton, J., Tymms, P., Vostanis, P., Belsky, J., Fonagy, P., Brown, A., Martin, A., Patalay, P., \& Wolpert, M. (2012). Journal of Psychoeducational Assessment,31(3), 247-257.

Denzin, N., Lincoln, Y. (2003). Strategies of Qualitative Inquiry Second Edition. Sage Publications, NY. 
Eiraldi, R., Mc Curdy, B., Khanna,M., Mautone,J., Jawad, A., Power,T., Cidav, Z., Cacia, J., Sugai, G. (2014). A cluster randomized trial to evaluate external support for the implementation of positive behavioural interventions and supports by school personnel. Implementation Science, 9(12), 1-13.

Eiraldi, R., Power, T., Schwartz, B., Keiffer, J., McCurdy, B., Mathen, M., \& Jawad, A. (2016). Examining Effectiveness of Group Cognitive-Behavioural Therapy for Externalizing and Internalizing Disorders in Urban Schools. Behavioural Modification, 40(4), 611639.

Garfat, T., \& Fulcher, L. (2016). The therapeutic use of Daily Life Events with families. Relational Child and Youth Care Practice, 26(4).

Gal, T. (2017). An ecological model of child and youth participation. Children and Youth Services Review, 79, 57-64.

Hart, K., Fabiano, G., Evans, S., Manos, M., Hannah, J., \& Vujnovic, R., (2017). Elementary and Middle School Teachers' Self-Reported Use of Positive Behaviourial Supports for Children With ADHD: A National Survey. Hammill Institute on Disabilities,25(4) 246-256.

Holton, J. (2010). The Coding Process and Its Challenges. Grounded Theory Review An international journal, 1(9).

Kilgus, S., Reinke, W., Jimerson, S. (2015). Understanding Mental Health Intervention and Assessment within a Multi-tiered Framework: Contemporary Science, Practice, and Policy. School Psychology Quarterly, 30(2), 159-165.

Leadbeater, B., Gladstone, E., \& Sukhawathanakul, P. (2015). Planning for Sustainability of an Evidence-Based Mental Health Promotion Program in Canadian Elementary Schools. Am J Community Psychology, 56(1-2), 120-33.

McIntosh, K., Ty, S., \& Miller, L. (2014). Effects of School-Wide Positive Behavioural Interventions and Supports on Internalizing Problems: Current Evidence and Future

Directions. Journal of Positive Behavior Interventions, 16(4) p. 209-218. DOI: $10.1177 / 10983007139491980$.

Mental Health Commission of Canada. (2015). School-Based Mental Health in Canada: A Final Report. Retrieved from https://www.mentalhealthcommission.ca/English/media/3319 . 
Miller, L., Short, C., Garland, J., Clark, S. (2010). The ABCs of CBT (Cognitive Behaviour Therapy): Evidence-Based Approaches to Children Anxiety in Public School Settings.

Journal of Counseling \& Development, 88(Fall), 432-439.

Miller G., Lean, D., Sweet, S., Moraes, S., \& Nelson, V. (2013). The Psychology School Mental Health Initiative: An Innovative Approach to the Delivery of School-Based Intervention Services. Canadian Journal of School Psychology, 28(1), 103-118.

Ministry of Education Ontario. (2019). Private Elementary and Secondary Schools. Retrieved from: http://www.edu.gov.on.ca/eng/general/elemsec/privsch/.

Moon, J., Williford, A., \& Mendenhall, A. (2017). Educators' perceptions of youth mental health: Implications for training and the promotion of mental health services in schools. Children and Youth Services Review, 73, 384-391.

NVivo 11, released 2015; NVivo 10, released in 2014.

O’Connor, E., Dearing, E., \& Collins, B. (2011). Teacher-Child Relationship and Behaviour Problem Trajectories in Elementary School. American Educational Research Journal, 48(1), 120-162.

Ontario Centre of Excellence for Child and Youth Mental Health. (2012). Evidence In Sight: Effective community mental health agency involvement in school-based services. Retrieved from: www.excellenceforchildandyouth.ca .

Paulus, F., Ohmann, S., Popow, C., (2016). Practitioner Review: School-based interventions in child mental health. Journal of Child Psychology and Psychiatry, 57(12), 1337-1359.

Reinke, W., Herman, K., \& Ialongo, N. (2012). Overview of Special Issue Developing and implementing integrated school-based mental health interventions. Advances in School Mental Health Promotion, 5(3), 158-160.

Responsive Classroom. (2019). About Responsive Classrooms. Retrieved from: https://www.responsiveclassroom.org/about/

Reupert, A. (2017) A socio-ecological framework for mental health and well-being, Advances in Mental Health, 15(2), 105-107, DOI: 10.1080/18387357.2017.1342902.

Rosa, E., Tudge, J. (2013). Urie Bronfenbrenner's Theory of Human Development: Its Evolution From Ecology to Bioecology. Journal of Family Theory \& Review, 5, pp. $243-258$.

Sanchez, A., Cornacchio, D., Poznanski, B., Golik, A., Chou, T., \& Comer, J. (2018). The 
Effectiveness of School-Based Mental Health Services for Elementary-Aged Children: A Meta-Analysis. Journal of the American Academy of Child \& Adolescent Psychiatry, 57(3), 153-165.

School Mental Health Assist (2018, Spring). The Brief The Administrators Voice

[web log newsletter]. Retrieved from: https://smh-assist.ca/resources/?tag=328

School Mental Health Ontario (2019, Spring). 2019 Action Plan: A Student-Centred Approach [web log newsletter]. Retrieved from: https://smh-assist.ca/blog/smho-action-plan/

Williams, J., Horvath, v., Wei, H., Van Dorn, R., \& Johnson-Reid, M. (2007). Teachers' Perspectives of Children's Mental Health Service Needs in Urban Elementary Schools. Proquest, 29(2), 95-107.

Zones of Regulation: A Concept to Foster Self-Regulation and Emotional Control. (2019).

Retrieved from: https://www.zonesofregulation.com/learn-more-about-the-zones.html 